\title{
Neutronics and Photonics Calculations for the Tokamak Experimental Power Reactor
}

\author{
R. T. Santoro \\ V. C. Baker \\ J. M. Barnes
}

\section{OAK RIDGE NATIONAL LABORATORY}

OPERATED BY UNION CARBIDE CORPORATION FOR THE ENERGY RESEARCH AND DEVELOPMENT ADMINISTRATION 


\section{DISCLAIMER}

This report was prepared as an account of work sponsored by an agency of the United States Government. Neither the United States Government nor any agency Thereof, nor any of their employees, makes any warranty, express or implied, or assumes any legal liability or responsibility for the accuracy, completeness, or usefulness of any information, apparatus, product, or process disclosed, or represents that its use would not infringe privately owned rights. Reference herein to any specific commercial product, process, or service by trade name, trademark, manufacturer, or otherwise does not necessarily constitute or imply its endorsement, recommendation, or favoring by the United States Government or any agency thereof. The views and opinions of authors expressed herein do not necessarily state or reflect those of the United States Government or any agency thereof. 


\section{DISCLAIMER}

Portions of this document may be illegible in electronic image products. Images are produced from the best available original document. 


\section{Printed in the United States of America. Available from National Technical Information Service \\ U.S. Department of Commerce 5285 Port Royal Rnad, Springfield, Virginia 22161 \\ Price: Printed Copy $\$ 4.50 ;$ Microfiche $\$ 3.00$}

This report was prepared as an account of work sponsored by the United States Government. Neither the United States nor the Energy Research and Development Administration/United States Nuclear Regulatory Commission, nor any of their employees, nor any of their contractors, subcontractors, or their employees, makes any warranty, express or implied, or assumes any legal liability or responsibility for the accuracy, completeness or usefulness of any information, apparatus, product or process disclosed, or represents that its use would not infringe privately owned rights. 
Contract No. W-7405-eng-26

Neutron Physics Division

\title{
NEUTRONICS AND PHOTONICS CALCULATIONS FOR THE TOKAMAK EXPERIMENTAL POWER REACTOR*
}

\author{
R. T. Santoro \\ V. C. Baker ${ }^{\dagger}$ \\ J. M. Barmes ${ }^{5}$
}

Date Published - March 1977

* Submitted for journal publication.

${ }^{\dagger}$ Graduate Research Assistant, Nuclear Engineering Department, University of Tennessee. Present address: Ebasco Services, Inc., New York, NY. $\$$ Computer Sciences Division.

OAK RIDGE NATIONAL LABORATORY

Oak Ridge; Tennessee 37830

operated by

UNION CARB IDE CORPORATION

for the

ENERGY RESEARCH AND DEVELOPMENT ADMINISTRATION

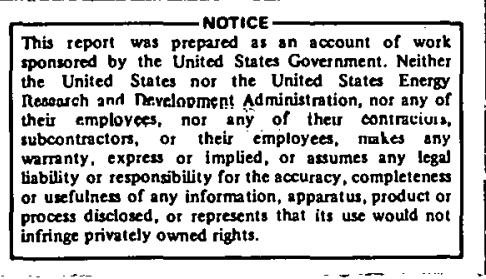


THIS PAGE

WAS INTENTIONALLY

LEFT BLANK 


\section{Acknowledgements}

The authors wish to thank E. S. Bettis and H. L. Watts for providing the mechanical designs for the EPR configurations considered in this study. The advice and comments of R. G. Alsmiller, Jr.,

W. W. Engle, Jr., and T. A. Gabriel throughout the course of this investigation are also appreciated. We would also like to express our gratitude to E. M. Oblow and R. W. Roussin for their assistance in interpreting some of the data reported here. One of US (VCB) wishes to thank W. E. Ford, III for providing him with the opportunity to participate in this project as part of his Graduate Research Training. 


\section{THIS PAGE}

\section{WAS INTENTIONALLY \\ LEFT BLANK}




\section{Abstract}

The results of one-dimensional neutronic and photonic calculations that compare the nuclear performance of blanket and shield designs proposed for use in the Tokamak Experimental Power Reactor are presented. The nuclear analysis was carried out for both nonbreeding and tritium-breeding blanket modules to compare the spatial variations of the radiation flux and energy distributions, nuclear heating, radiation damage, and tritium breeding. Nonbreeding blanket modules that contain potassium plus SS-316 or potassium only as the energy-absorbing medium and breeding blankets that use natural lithium as the fertile material were evaluated as a function of the first-wall cooling scheme. 


\section{INTRODUCTION}

To design a D-T burning thermonuclear power reactor requires a collaborative effort involving plasma, mechanical, electromagnetic, materials, and nuclear research. The nuclear-research effort provides much of the basic data to the other research areas that are essential for selecting suitable materials and for optimizing the blanket and shield design, as well as other components in the reactor. This paper summarizes the results of one-dimensional neutronics and photonics calculations that were carried out in support of the conceptual design of the Tokamak Experimental Power Reactor (EPR) being undertaken at the Oak Ridge National Laboratory.

The blanket and shield designs compared in this paper and proposed for use in the EPR evolved, in part, from the results of a scoping studyl, 2 where in several blanket and shield concepts were evaluated in terms of the EPR design objectives. ${ }^{3}$ The design criteria specified that the blanket and shield in the EPR have the capabilities of (1) recovering $>90 \%$ of the kinetic energy of the fusion neutrons in the blanket and converting this energy, along with that of secondary gamma rays produced by the neutrons, into heat at useful temperatures; (2) reducing the intensity of the plasma neutrons and providing sufficient radiation shielding to minimize the nuclear heating and radiation damage in the superconducting toroidal field (TF) coils; and (3) demonstrating in a few experimental blanket modules tritium. breeding. A blanket and shield design that resulted from the scoping study was incorporated into the EPR Reference Design. ${ }^{4,5}$ However, in the continuing research effort on the EPR, several changes were made in important reactor components, including the blanket. 
For completeness, a detailed nuclear analysis was carried out for the blanket and shield design described in Refs. 4 and 5 . Calculations, in which stainless steel 316 (SS-316) was used as the structural material and in which a more accurate representation for the TF coils was incorporated, were made for both nonbreeding and tritium-breeding blanket modules. The results of these more detailed calculations, along with mechanical, thermodynamic, and hydraulic analyses, revealed that the blanket could not be adequately cooled if the neutron loading on the first wall exceeded $\sim 0.2 \mathrm{MW} / \mathrm{m}^{2}$. The design was subsequently modified to include water-filled cooling channels adjacent to the first wall. The water-cooling channels reduce the heat loads and temperature gradients in the first wall to manageable levels where the neutron wall loading is extended to $1 \mathrm{MW} / \mathrm{m}^{2}$. Some calculated results are also given for another blanket concept using sodium hydroxide as an alternative to the water coolant. The water-cooled design is currently preferred so most of the calculated results are given for this concept, and the nuclear performance of the older reference design and that of the blanket cooled by sodium hydroxide are compared relative to this design.

The nuclear performances of the EPR when each type of blanket design was used for both the nonbreeding and the tritium breeding configurations are compared in terms of (1) the spatial variations in the omnidirectional neutron and gamma-ray fluxes and energy distributions throughout the reactor assembly; (2) the spatial distributions and integrals of the nuclear heating, particularly in the blanket and TF coil windings; (3) the neutron-induced radiation damage in the reactor structural materials, particularly the first structural wall and the conductors and insulators in the TF coil; and (4) the tritium breeding in the experimental blanket modules. 
A description of the reactor model and the details of the calculations are given in sect. II. The results are presented and discussed in sect. III.

\section{THE REACTOR MODEL AND DETAILS OF THE CALCULATIONS}

Reactor Configuration and Composition of Materials

A schematic representation of the EPR used in carrying out the onedimensional neutronics and photonics calculations is shown in Fig. 1. The reactor is represented in a cylindrical geometry about the plasma centerline. The plasma has a nominal radius of $223.7 \mathrm{~cm}$ and is surrounded by a $0.3-\mathrm{cm}-$ thick graphite curtain. ${ }^{6}$ Beyond this liner at an inner radius of $225 \mathrm{~cm}$ is the $51.5-\mathrm{cm}$-thick blanket, which is followed by a $30-\mathrm{cm}$-thick void region and surrounded by a $48.5-\mathrm{cm}-$ thick TF coil shield. The blanket and shield, excluding the void that separates them, have a combined thickness of $100 \mathrm{~cm}$. The TF coils that surround the blanket and shield are 62.2-cm-thick and are separated from the outer surface of the shield by a $10-\mathrm{cm}-$ thick gap. Detailed representations of these reactor components and discussions of the philosophy of their design are found elsewhere, ${ }^{4,7,8}$ so only the salient features of the blanket, shield, and TF coils necessary for interpreting the nuclear calculations are included here.

The graphite curtain ${ }^{6}$ that separates the plasma from the first wall of the blanket protects the wall from the damaging effects of low-energy photons, X-rays, and charged particles that are emitted from the plasma. Simultaneously, the graphite curtain prevents metallic atoms and chunks of wall material that are knocked loose from the first wall from entering the plasma. The validity of using a low-Z material for the curtain has not been fully resolved, and further research is required to define the composition, thickness, and location relative to the first wall of impurity 




Fig. 1 Schematic diagram of the EPR Blanket-Shield and TF Coil. 
control materials. The graphite curtain is included in the calculational model to obtain approximate results of its inclusion on the nuclear performance of the blanket.

The blanket consists of 60 autonomous segments that form the torus. Each blanket segment is composed of three compartments: an energy absorber (and breeding section when lithium is used), a reflector, and a gamima-ray shield: The blanket: superstructure, including the first wall, is SS-316, and in the calculations the composition of SS-316 was taken to be $63.6 \% \mathrm{Fe}$, $18 \% \mathrm{Cr}, 13 \% \mathrm{Ni}, 2.6 \% \mathrm{Mo}, 1.9 \% \mathrm{Mn}$, and $0.9 \% \mathrm{Si}, \mathrm{Ti}$, and $\mathrm{C}$.

The choice of SS-316 as the structural and first-wall material was based on its economy, availability, and suitability for use in the EPR without limiting project goals, performance, and schedules. It is ai so compatible with both potassium and lithium, the energy absorbing and fertile materials chosen for use in the nonbreeding and tritium-breeding blanket modules, respectively. The alloy can also endure, within certain restrictions, the radiation and temperature environments in the reactor. It is not within the scope of this paper to argue the merits and demerits of using SS-316. Arguments for its selection for use in the EPR may be found in Ref. 4. Comparative studies of different iron alloys, as well. as other materials, for CTR applifation may be found elsewhere. ${ }^{9-12}$

'The energy-absorbing compartment in the blanket is $25 \mathrm{~cm}$ thick and is followed by a 10-cm-thick graphite neutron reflector. The gamma-ray shield at the rear of the blanket assembly consists of alternating layers of stainless steel and coolant. The dimensions and compositions of the three blanket designs are compared in Table I. The configuration labeled "Reference Design" corresponds to that described in Refs. 4 and 5 . Note that in the 
TABLE I

EPR Reference Design Blanket Assemblies

\begin{tabular}{|c|c|c|c|c|c|c|c|c|c|}
\hline \multirow[b]{2}{*}{ Zone } & \multicolumn{3}{|c|}{ Reference Design, Water Cooled } & \multicolumn{3}{|c|}{ Reference Designa } & \multicolumn{3}{|c|}{ Feference Design, $\mathrm{NaOH}$ Cooled } \\
\hline & $\begin{array}{c}\text { Material } \\
\text { Composition }\end{array}$ & $\begin{array}{c}\text { Outer } \\
\text { Radius } \\
(\mathrm{cm})\end{array}$ & $\begin{array}{c}\text { Thickness } \\
(\mathrm{cm})\end{array}$ & $\begin{array}{c}\text { Material } \\
\text { Composition }\end{array}$ & $\begin{array}{c}\text { Outer } \\
\text { Radius } \\
(\mathrm{cm})\end{array}$ & $\begin{array}{c}\text { Thickness } \\
(\mathrm{cm})\end{array}$ & $\begin{array}{c}\text { Material } \\
\text { Composition }\end{array}$ & $\begin{array}{c}\text { Outer } \\
\text { Radius } \\
(\mathrm{cm})\end{array}$ & $\begin{array}{c}\text { Thickness } \\
(\mathrm{cm})\end{array}$ \\
\hline $\begin{array}{l}1 \\
2 \\
3 \\
4 \\
5 \\
6 \\
7 \\
8 \\
9 \\
10 \\
11 \\
12 \\
13 \\
14 \\
15 \\
16 \\
17 \\
18 \\
19 \\
20 \\
21 \\
22 \\
23 \\
24 \\
25 \\
26 \\
27 \\
28\end{array}$ & $\begin{array}{l}\text { Plasma } \\
\text { Carbon } \\
\text { Water } \\
\text { SS-316 } \\
\text { Absorber } \\
\text { SS-316 } \\
\text { Carbon } \\
\text { SS-316 } \\
\text { Coolant } \\
\text { SS-316 } \\
\text { Coolant } \\
\text { SS-316 } \\
\text { Coolant } \\
\text { SS-316 } \\
\text { Coolant } \\
\text { SS-316 } \\
- \\
- \\
- \\
- \\
- \\
- \\
- \\
- \\
- \\
- \\
- \\
- \\
-\end{array}$ & $\begin{array}{c}224.07 \\
224.37 \\
225.100 \\
226.11 \\
251.11 \\
252.11 \\
262.11 \\
263.38 \\
265.88 \\
268.38 \\
268.88 \\
271.38 \\
271.88 \\
274.33 \\
274.83 \\
276.53 \\
- \\
- \\
- \\
- \\
- \\
- \\
- \\
- \\
- \\
- \\
- \\
-\end{array}$ & $\begin{array}{r}224.07 \\
0.30 \\
0.63 \\
1.11 \\
25.00 \\
1.00 \\
10.00 \\
1.27 \\
2.50 \\
3.00 \\
0.50 \\
2.50 \\
0.50 \\
2.50 \\
0.50 \\
1.62 \\
- \\
- \\
- \\
- \\
- \\
- \\
- \\
- \\
- \\
- \\
- \\
- \\
- \\
-\end{array}$ & $\begin{array}{l}\text { Plasma } \\
\text { Carbon } \\
\text { Void. } \\
\text { SS-316 } \\
\text { Absorber } \\
\text { SS-316 } \\
\text { Carbon } \\
\text { SS-316 } \\
\text { Coolant } \\
\text { SS-316 } \\
\text { Coolant } \\
\text { SS-316 } \\
\text { Coolant } \\
\text { SS-316 } \\
\text { Coolant } \\
\text { SS-316 } \\
- \\
- \\
- \\
- \\
- \\
- \\
- \\
- \\
- \\
- \\
- \\
-\end{array}$ & $\begin{array}{c}223.70 \\
224.00 \\
225.00 \\
226.11 \\
251.11 \\
252.11 \\
262.11 \\
263.38 \\
265.88 \\
268.38 \\
268.88 \\
271.38 \\
271.88 \\
274.38 \\
274.88 \\
276.50 \\
- \\
- \\
- \\
- \\
- \\
- \\
- \\
- \\
- \\
- \\
- \\
-\end{array}$ & $\begin{array}{r}223.70 \\
0.30 \\
1.00 \\
1.11 \\
25.00 \\
1.00 \\
10.00 \\
1.27 \\
2.50 \\
3.00 \\
0.50 \\
2.50 \\
0.50 \\
2.50 \\
0.50 \\
1.62 \\
- \\
- \\
- \\
- \\
- \\
- \\
- \\
- \\
- \\
- \\
- \\
-\end{array}$ & $\begin{array}{l}\text { Plasma } \\
\text { Carbon } \\
\text { NaOH } \\
\text { SS-316 } \\
\text { Absorber } \\
\text { SS-316 } \\
\mathrm{NaOH} \\
\text { SS-316 } \\
\text { Absorber } \\
\text { SS-316 } \\
\mathrm{NaOH} \\
\text { SS-316 } \\
\text { Absorber } \\
\text { SS-316 } \\
\mathrm{Carbon} \\
\text { SS-316 } \\
\text { Absorber } \\
\text { SS-316 } \\
\text { NaOH } \\
\text { SS-316 } \\
\text { Coolant } \\
\text { SS-316 } \\
\text { CoOlant } \\
\text { SS-316 } \\
\text { CoO?ant } \\
\text { SS-316 } \\
\text { CoOlant } \\
\text { SS-316 }\end{array}$ & $\begin{array}{l}223.70 \\
224.00 \\
224.64 \\
225.28 \\
227.78 \\
227.82 \\
227.92 \\
227.96 \\
247.96 \\
248.00 \\
248.10 \\
248.14 \\
250.64 \\
251.64 \\
261.64 \\
262.64 \\
266.64 \\
266.68 \\
266.78 \\
266.82 \\
268.00 \\
270.50 \\
271.00 \\
273.50 \\
274.00 \\
276.50 \\
277.00 \\
278.16\end{array}$ & $\begin{array}{r}223.70 \\
0.30 \\
0.64 \\
0.64 \\
2.50 \\
0.04 \\
0.10 \\
0.04 \\
20.00 \\
0.04 \\
0.10 \\
0.04 \\
2.50 \\
1.00 \\
10.00 \\
1.00 \\
4.00 \\
0.04 \\
0.10 \\
0.04 \\
1.18 \\
2.50 \\
0.50 \\
2.50 \\
0.50 \\
2.50 \\
0.50 \\
1.16\end{array}$ \\
\hline
\end{tabular}

a. See Refs. 4 and 5 . 
water-cooled reference design the dimension of the plasma radius is slightly larger (by $0.37 \mathrm{~cm}$ ) than in the design without water cooling. Also note that the blanket thickness in the sodium-hydroxide-cooled blanket is slightly larger $(53.52 \mathrm{~cm})$ than in the other designs and the first-wall inner radius is $225.28 \mathrm{~cm}$. The dimensional differences among the three blanket designs are small and have no significant influence on the calculated results and comparisons.

$\therefore$

... The compositions of the absorher and coolant materials used in blankets in the nonbreeding and breeding modules are given in Table. II. "In the nonbreeding modules, both potassium and potassium plus stainless steel in the form: of spheres were considered. Natural lithium was the fertile material used in the breeding modules. Potassium and lithium are both easily cooled and have thermal conductivity properties that permit satisfactory exchange of heat between the first wall and blanket-cooling tubes (not shown in Fig. 1) that are interspersed in the blanket. ${ }^{4}$

Neutronic and photonic analyses were also carried out for blankets using sodium rather than potassium as the absorber. The nuclear performance of the reactor using sodium as the blanket was found to be similar to that using potassium. However, the use of sodium as the energy absorbing material was rejected principally because the energetic gamma radiation from sodium isotopes produced in the neutron environment would unduly complicate the shielding and remote maintenance of the blanket assembly.

The graphite reflector is used primarily to enhance the tritium breeding by reflecting neutrons back into the thick energy-absorbing compartment in the blanket when lithium is used to breed tritium. Graphite is not essential in the nonbreeding modules, but it is retained in the design to maintain symmetry. 
TABLE II

Blanket Absorber and Gamma-Ray Shield Coolant Materials

\begin{tabular}{|c|c|c|}
\hline Blanket Type & Absorber ${ }^{\mathrm{a}}$ & Coolant \\
\hline \multirow[t]{2}{*}{ Nonbreeding } & Potassium $(35 \mathrm{v} / 0)$ SS-316 (65 v/0) & Potassium \\
\hline & Potassium & Potassium \\
\hline Tritium Breeding & Lithium ${ }^{\mathrm{c}}$ & Lithium ${ }^{c}$ \\
\hline \multicolumn{3}{|c|}{$\begin{array}{l}\text { a. In the breeding-type blanket module, the absorber compartment } \\
\text { has the dual function of recovering the kinetic energy of the } \\
\text { fusion neutrons and breeding tritium. }\end{array}$} \\
\hline \multicolumn{3}{|c|}{ b. The cooling material for the blanket gamma-ray shield compartment } \\
\hline
\end{tabular}


Because the blanket does not sufficiently attenuate the neutrons and secondary gama rays and provide adequate protection for the superconducting Tf coils against nuclear heating and radiation damage and because a thermal barrier is required between the high-temperature bianket and the cryogenic coils, the 48.5-cm-thick shield must surround the blanket in the space between the coils and the blanket. The shield is comprised of a $32-\mathrm{cm}$-thick compartment filled with borated water $(35 \mathrm{v} / 0)$ and $\mathrm{sS}-316$ spheres $(65 \mathrm{v} / 0)$ surrounded by a 6.5-cm-thick lead 1 iner. The shicld is supported by a 5-cmthick SS-316 structural layer on both the inner and outer radial surfaces.

Surrounding the blanket and shield are the superconducting TF coils. The coil windings are $52.2 \mathrm{~cm}$ thick and are supported by 5 -cm-thick stainlesssteel supports on the radial surfaces. The coil-winding assemblies were approximated in the calculations by alternating stainless steel and conducting material layers $1: 62$ and $1.28 \mathrm{~cm}$ thick, respectively. The composition of the conductor is given in the insert in Fig. 1. "In the calculations, the materials in the conductor were homogenized. Modeling the coil in this manner accounts for, in an approximate way, the conductors and the ir supports. Additional details concerning the TF coils and other electromagnetic systems mäy be found in Ref': 4 .

\section{Methods of Calculation}

All of the neutronics and photonics calculations were carried out using the one-dimensional discrete ordinates code ANISN, 13 a $\mathrm{P}_{3}$ scattering expansion, and an $\mathrm{S}_{12}$ angular quadrature. The transport cross sections were taken from the coupled $100 \mathrm{n}-21$ r cross-section 1 ibrary prepared for EPR calculations 14,15 that were compiled from the latest available ENDF/B-IV data. The GAM-II16 99 epithermal and fast groups, plus a thermal group, 
comprise the neutron energy group structure. The neutron- and photonproduction cross sections were weighted with an $\mathrm{E}^{-1}$ function for neutrons with energies $>5 \mathrm{kT}$ and with a Maxwellian distribution peaked at $800^{\circ} \mathrm{K}$ for neutrons with energies $\leq 5 \mathrm{kT}$. All resonance nuclides were treated as infinitely dilute. The photon-interaction cross sections were flat-weighted.

Energy deposition in the reactor blanket, shield, and TF coils was estimated with neutron kerma factors obtained from MACK ${ }^{17}$ and MACKLIB ${ }^{18}$ and photon kerma factors generated by SMUG. ${ }^{19}$ Rardiation damage was calculated with the newly developed data base RECOIL ${ }^{20}$ that generates atomic-displacement and gas-production cross sections in multigroup format from ENDF/B-IV point cross-section data.

The nuclear performance of the EPR was estimated using the parameters summarized in Table III. Except for the physical dimensions of the reactor, all other values were obtained for an assumed neutron wall loading of $1 \mathrm{MW} / \mathrm{m}^{2}$ and an average neutron energy of $14.1 \mathrm{MeV}$ per D-T fusion.

All of the comparisons are based on the parameters given in Table III. As noted above, the reference design without water cooling for the first wall is not suitable for use in an operating reactor at this neutron wall loading. However, the results, in general, can be scaled as a function of neutron wall loading, so the results are compared in this manner only for convenientic. 
TABLE III

EPR Reference Design Parameters

\section{Plasma Dimensions}

Major radius (m)

6.75

Minor radius (m)

2,237

Plasma volume $\left(\mathrm{cm}^{3}\right)$

$6.67 \times 10^{8}$

Plasma surface area $\left(\mathrm{cm}^{2}\right)$

$5.96 \times 10^{6}$

Toroidal length $(\mathrm{cm})$

$4.24 \times 10^{3}$

\section{Reactor Power Parameters}

Neutron wall loading $\left(\mathrm{MW} / \mathrm{m}^{2}\right)$

1.0

Wall loading $\left(\mathrm{n} / \mathrm{cm}^{2} / \mathrm{sec}\right)$

$4.42: \times 10^{13}$

Neutrons per. sec per $\mathrm{cm}^{\mathrm{a}}$

$6.21 \times 10^{16}$

Reactor power. (MW) ${ }^{b}$

595

a. The one-dimensional calculations were normalized to one neutron per sec per $\mathrm{cm}$.

b. The reactor power was inferred from the neutron wall loading and the reactor dimensions... 


\section{DISCUSSION OF RESULTS}

Detailed one-dimensional nuclear analyses were carried out for each of the EPR configurations summarized in Table I. The reference-design reactor with water cooling adjacent to the first structural wall was generally accepted to be the preferred design. The two remaining reactor models each have features which, under appropriate conditions, would also make them desirable for the EPR. In terms of the neutronics analyses, the designs are quite simflar, so, in general, the detailed results of the calculations reported here will pertain to the water-cooled design and, when relevant, the differences in the nuclear performances in the other designs will be noted. Flux and Energy Distributions

The spatial distributions of the integral neutron, secondary gamma-ray, and total (neutron plus gamma ray) fluxes as a function of the radial position in the blanket and shield in the reference-design reactor (water cooled) are shown in Fig. 2 when potassium plus SS-316, lithium, and potassium only are used as the energy-absorbing materials in the blanket assembly. These data were obtained by integrating the neutron and secondary gamma-ray omnidirectional fluxes per unit energy over the appropriate particle energy range at each radial interval used in the radiation-transport calculation. The curves have been hand-smoothed to more clearly illuminate the spatial variation in the integral flux for the two radiation modes.

A more rapid attenuation of the integral neutron flux takes place in the energy-absorbing compartment of the blanket containing potassium plus SS-316 than in the blankets containing lithium or potassium. The large concentration of stainless steel $(65 \mathrm{v} / 0)$ in this compartment effectively 


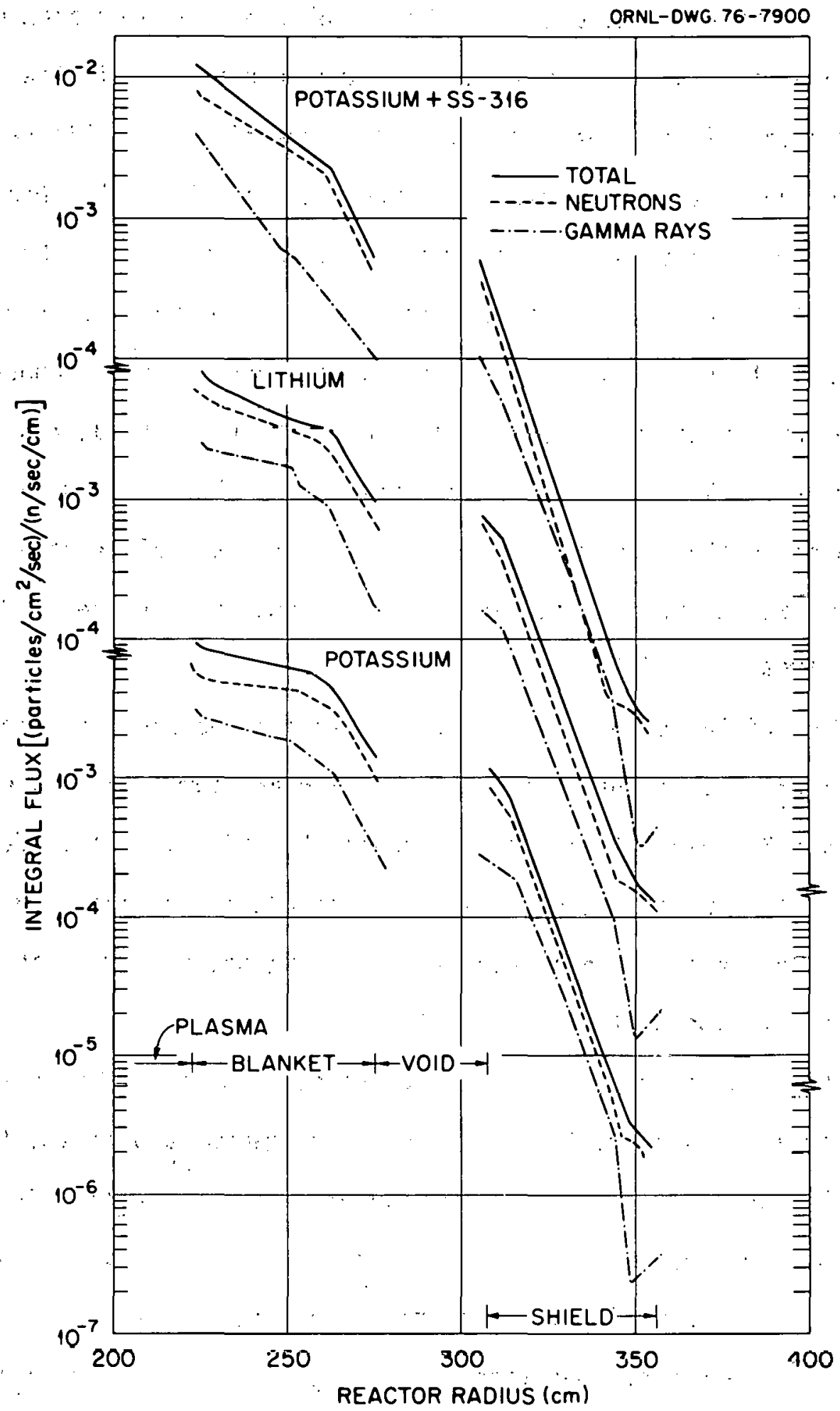

Fig. 2 Spatial Distributions of the Integral Particle Fluxes in the Blanket and Shield of the Water-Cooled Reference Design Reactor When Potassium plus SS-316, Lithium, and Potassium Oniy are Used as the Energy Absorber. 
attenuates the neutrons emitted from the plasma. In each blanket, the integral neutron flux decreases in the graphite reflector followed by a fairly rapid decrease in the gamma-ray shield of the blanket. This rapid decrease again is due to the large amount of stainless steel in the shield.

The rapid decrease in the integral gamma-ray flux in the potassium plus SS-316 blanket is due to the presence of the stainless steel. The higher effective $Z$ value of the material in this blanket compared to the lithium- or potassium-filled assemby leade to the more rapid attenuation in the gamma-ray flux. The abrupt changes in the slopes of the integral gammaray fluxes in the lithium- and potassium-laden assemblies at a radius of $\sim 265 \mathrm{~cm}$ are due to the passage of the photons through the SS-316 layers in the gamma-ray shield.

The shield composition and thickness are the same for the three cases shown in Fig. 2. In each case, the neutron and gamma-ray fluxes are reduced by $\sim 3$ orders of magnitude through the shield. The differences in the slopes of the curves, as well as the magnitude at the inner surface of the shield, are due to the differences in the average energy of the neutrons or gamma rays incident on the shield.

The blanket assembly has the principal function of recovering the energy of the fusion neutrons and secondary gamma rays in the form of usable heat. In the case of the lithium blanket, tritium breeding is also a requirement. However, of equal importance is the effectiveness of the blanket. and shield in minimizing the radiation flux incident on the TF coils within the constraints of specified thickness, heat-recovery capability, and, if necessary, tritium breeding. The radiation-attenuating effectiveness of the blanket-shield cases shown in Fig. 2 is given in Table IV as a function 


\section{Table IV}

$\therefore$

Radiation Attenuating Capability of the Blanket and Shield as a Function of Absorber Material in the

Reference Design Reactor (Water-Cooled)

\begin{tabular}{|c|c|c|c|}
\hline 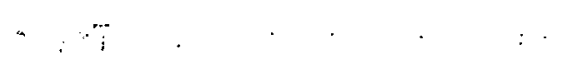 & \multicolumn{3}{|c|}{ Absorber Material } \\
\hline$\because \cdots ;$ & $k+S S-316$ & Li & K \\
\hline Location & \multicolumn{3}{|c|}{ Fraction of the Total Flux } \\
\hline First st.rurtural wạll & 1.00 & 1.00 & 1.00 \\
\hline Rear of the blanket & $3.74 \times 10^{-2}$ & $9.36 \times 10^{-2}$ & $1.23 \times 10^{-1}$ \\
\hline Rear of the shield & $1.88 \times 10^{-5}$ & $1.52 \times 10^{-4}$ & $2.10 \times 10^{-4}$ \\
\hline Attenuating effectiveness ${ }^{a}$ & 1.00 & 0.12 & 0.09 \\
\hline
\end{tabular}

a. Relative to the blanket with $K+S S-316$ as the absorber material. 
of the energy-absorbing material. The values given in the table are the fractions of the total flux relative to the flux at the first structural wall. The blanket containing potassium plus SS-316 is 2.5 times more effective in attenuating the radiation than the blanket containing lithium and 3.3 times more effective than the one containing potassium. The combined radiation attenuating effectiveness of the three designs are compared in the last row of the table. When lithium is used as the energy absorber, the blanket and shield are only $12 \%$ as effective as the assembly containing potassium plus SS-316, and when potassium only is used in the energy-absurbiny compartment, the radiation-attenuating effectiveness is reduced to $9 \%$.

The spatial distributions of the integral neutron and gamma-ray fluxes as a function of radial position in the blanket and shield of the referencedesign reactor (without water cooling) are essentially the same as those shown in Fig. 2 for the same blanket absorber materials. The differences in the flux distributions between the two designs are due primarily to the variations in the neutron and gamma-ray spectra that result from the presence of the $0.63-\mathrm{cm}-$ thick water-cooling channel that differentiates the two reactor designs. The radiation attenuating effectiveness of the blanket and shield as a function of blanket absorber material without water cooling is very nearly the same as that given in Table IV.

The spatial distributions of the flux were also obtained for the reference design with sodium hydroxide as the cooling material, but only when lithium was used as the energy-absorbing material. The flux distributions and the radiation attenuating capability for this reactor were also essentially the same as those obtained for the lithium-laden blankets in the two reactor designs cited above. 
The space and energy dependences of the neutron scalar flux in the reference-design reactor (water cooled) when potassium plus SS-316 and lithium are used as the energy-absorbing material in the blanket are shown in Fig. $3(a)$ and (b), respectively. ${ }^{21}$ The radial dimensions of the reactor are plotted in equal intervals corresponding to the number of radial mesh intervals used in the ANISN $\operatorname{code}^{13}$ to define the blanket, shield, and TF coils. This results in a compression of the radial extent of the reactor. The energy scale is plotted in lethargy intervals obtained with the relation $u=\ln \left(E_{u} / E_{l}\right)$ evaluated at the upper $\left(E_{u}\right)$ and lower $\left(E_{l}\right)$ energy bounds of each neutron group.14,15 The neutron flux in each spatial interval has been normalized to unity. This normalization removes effects of the spatial attenuation of the flux and magnifies its energy dependence.

The 14-MeV neutrons produced in the plasma are attenuated rapidly as they pass through the reactor, as shown by the rapidly decreasing amplitude of the peaks along the left edges of both (a) and (b) of Fig. 3. These neutrons lose energy in the blanket containing potassium plus SS-316 as the energy absorber primarily through inelastic collisions with the absorber nuclei, particularly iron. The peaks in the distributions occur at crosssection minima and show the energy intervals through which the neutrons stream, suffering the least number of reactions. The valleys, or depressions, indicate the energy intervals in which neutron interactions are greatest. The sharply defined valleys occur at cross-section resonances. The two large peaks arising along the inner spatial intervals are due to neutron streaming in the 24- and $80-\mathrm{keV}$ cross-section minima in iron. Other crosssection minima and resonances in iron are apparent but are less accentuated because of compensating neutron interactions taking place in the potassium or with other nuclei that comprise stainless steel. 
ORNL-DWG 76-20882

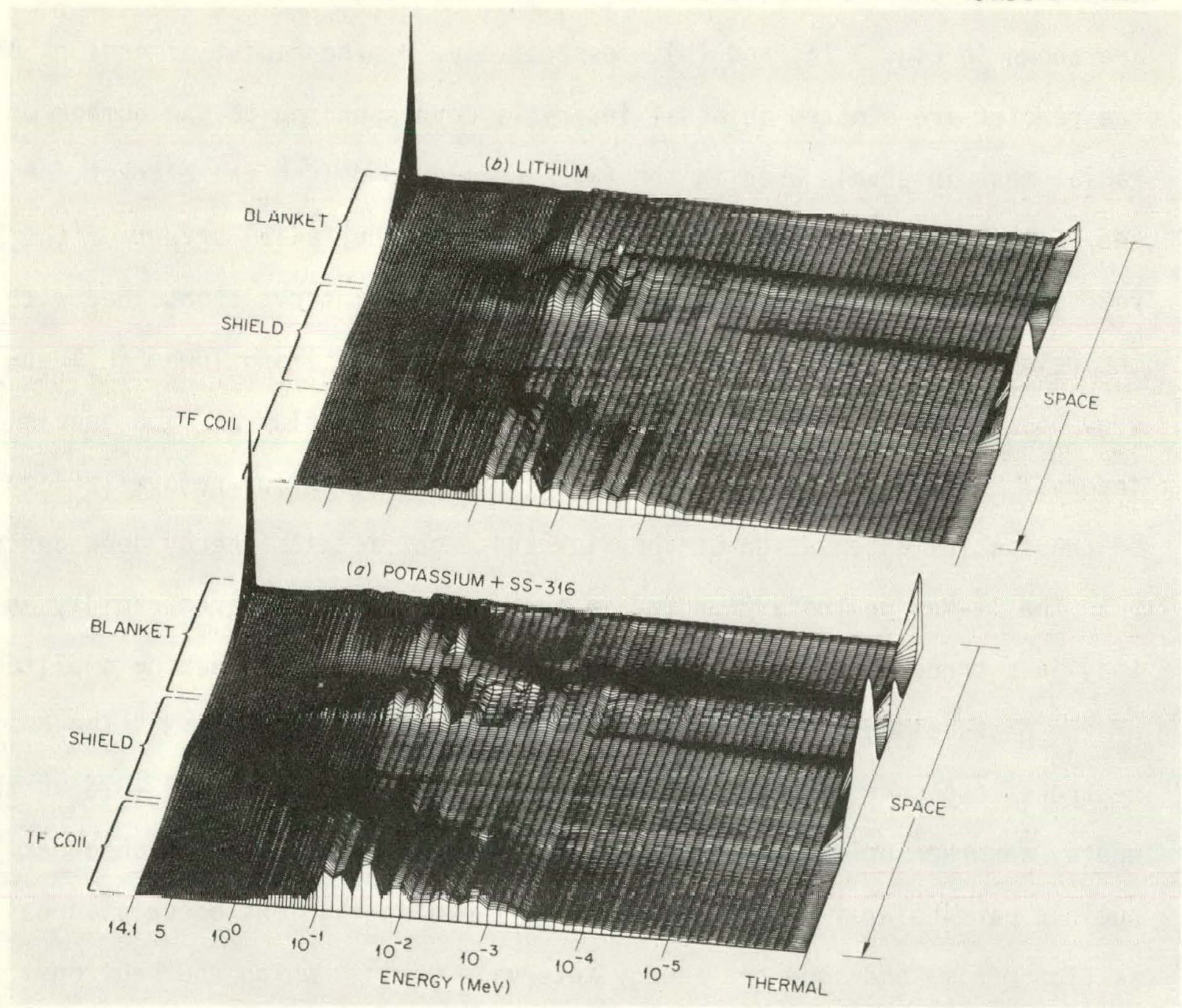

Fig. 3 Space and Energy Dependences of the Neutron Scalar Flux in the Water-Cooled Reterence Design Reactor When Potassium Hlus SS-316 and Lithium are Used as the Energy Absorber. 
In the energy-absorbing compartment of the blanket containing lithium, there is considerably less structure in the flux distributions. The energy dependence follows that predicted by the total, neutron cross section of natural lithium. The depression in the curves between $100 \mathrm{keV}$ and $1 \mathrm{MeV}$ is due to ${ }^{6} \mathrm{Li}(\mathrm{n}, \alpha)$ reactions taking place in the large resonance about $240 \mathrm{keV}$ that is characteristic of this reaction.

The neutrons that leak through the energy-absorbing compartment of each blanket in Fig. 3 are moderated in the graphite reflcctor.. The spare and energy dependences of the flux in the graphite follow the energy. dependence of the neutron cross section for this material. The thermal-: neutron flux in the graphite in Fig. $3(a)$ is larger than that in Fig. 3 (b) and is due to the difference in the average energy of the neutrons incident on the reflector in each case.

The structure in the flux distributions in the blanket gamma-ray: shield and in the stainless-steel: support at the inner surface of the shield shows the :cross-section minima and resonances in stainless steel. The neutrons leak into the borated-water and stainless-steel section of the shield; mainly through the $24-$ and $80-k e V$ cross-section minima in iron. However, these neutrons are rapidly moderated and thermalized by the borated water, giving rise to the large:flux distributions in the thermal-energy group in each design.: Again; the difference in the magnitude of the flux in each case is due to the differences in the energy distribution of the neutrons -incident on this section of the shield.

The flux distributions in the rear of the shield and through the TF coil section show the characteristics of neutron transport in stainless steel. The structure in the curves below $10 \mathrm{keV}$ is due to neutron transport in the 
coil-conductor material, particularly through the 7.5-, 9.1-, and 9.5-keV cross-section minima in copper.

The space and energy dependences of the secondary gamma-ray flux per unit energy in the two reactor configurations are shown in Fig. 4 (a) and (b), respectively.21. These data are plotted using the same spatial mesh as in Fig. 3 but with the energy scale plotted in intervals spaced in proportion to the widths of the gamma-ray energy group structure.11:15 The gamma-ray spectra are normalized to unity in each spatial interval to remove the effects of attenuation, and these data are plotted at the midpoint of each energy group.

The distributions in Fig. 4 show the prndurtion of gamma radiatiun throughout the reactor. The peaks at $7 \mathrm{MeV}$ that occur in the energyabsorbing compartment of the blanket containing potassium plus SS-316 show the photon production from thermal-neutron-capture reactions in the iron nuclei in the stainless steel. Note that these gamma-rays are not produced in the blanket containing lithium as the energy absorber. The large peaks rising in the low-energy intervals at and beluw 1.25 MeV show the gamma radiation through $\left(n, n^{\prime}\right)$ reactions. The peaks in the spectra in the energy interval about $1.25 \mathrm{MeV}$ are due to inelastic neutron reactions in chromium (1.44 MeV) and in nickel (1.33 MeV), and, the larger peaks in the spectra in the interval about $0.7 \mathrm{MeV}$ correspond to $0.85-\mathrm{MeV}$ gamma-rays from inelastic neutron reactions with iron nuclei. These photon-producing reactions occur throughout the potassium-plus-SS-316-filled compartment. These photons also appear in the lithium absorber, but in this case they are produced elsewhere in the reactor and leak into the lithium. The large amplitude peaks in the lithium absorber in the energy interval about $0.3 \mathrm{MeV}$ are the 


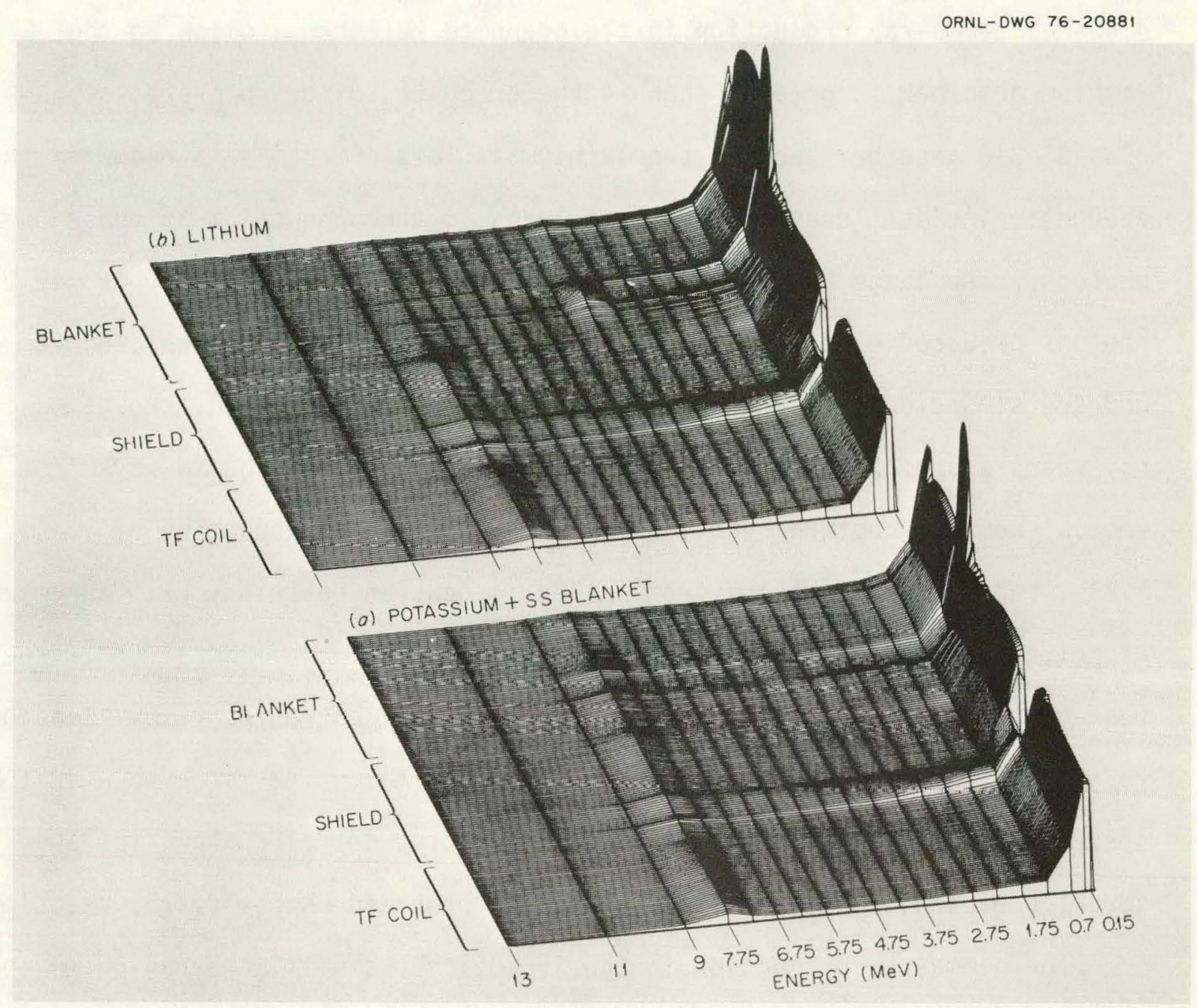

Fig. 4 Space and Energy Dependences of the Secondary Gamma-Ray Flux per Unit Energy in the Water-Cooled Reference Design Reactor When Potassium Plus SS-316 and Lithium are Used as the Energy Absorber. 
0.48-MeV gamma-rays from $\left(n, n^{\prime}\right)$ reaction in ${ }^{7} \mathrm{Li}$.

The secondary gamma-ray spectra throughout the remaining sections of both reactor configurations in Fig. 4. are very similar in shape. The 4.43-MeV gamma-ray production in the graphite reflector following the lithium absorber is greater than in the graphite following the potassiumplus-SS-316 absorber because the lithium is less effective in reducing the energetic incident neutron flux that leads to the production of these photons. The large peak at low energy in the graphite reflector is due to photons produced elsewhere in the reactor that pass through the graphite and are slowed down in the reflector. Throughout the shield, the gammaray spectra are characterized by the production of 7-MeV gamma rays from therma1-neutron-capture reactions by iron and by the production of 1.44-, 1.33-, and $0.85-\mathrm{MeV}$ photons from inelastic neutron reactions with chromium, nickel, and iron nuclei in the stainless steel. In the lead liner at the rear of the shield, photon production occurs via neutron reactions leading to the excited states from $3.0 \mathrm{MeV}$ down to $0.3 \mathrm{MeV}$. The large hole in the spectral distributions in the lead at low photon energies shows the absorption of photons by the lead through Compton and photoelectric reactions.

The gamma-ray production in the TF coil shows similar behavior to that in the blarket and is due to low-energy neutron inelastic reactions with the conductor materials and the stainless-steel structure. The 7-MeV photons are those produced from thermal neutron capture in iron and to a lesser extent in the copper and aluminum of the conductor. The low-energy photons are produced by neutrons having energies $>850 \mathrm{keV}$ leading to inelastic neutron scattering in iron, aluminum, and copper. 


\section{Nuclear Heating}

The spatial distributions of the nuclear heating rates in the referencedesign reactor (water cooled) are shown in Fig: 5 when potassium plus SS-316, lithium, and potassium only are used as the energy-absorbing materials in the blanket assembly (see Table II). The solid curves show the total heating rates (neutrons plus secondary gamma rays) and the curves bearing tick marks show the heating rates from neutrons only. Note that the ordinate has been broken in order to display the results for the three cases in the same figure.

The peak heating rate occurs in the first SS-316 structural wall in each of the cases shown in the figure. At a neutron wall loading of $1 \mathrm{MW} / \mathrm{m}^{2}$, the peak heating rates are $11.7,10.4$, and $12.0 \mathrm{~W} / \mathrm{cm}^{3}$ for the potassium plus SS-316, the lithium, and the potassium configurations, respectively. In the blanket assembly containing potassium plus SS-376, the nuclear heating rate decreases by approximately three orders of magnitude through the blanket. The large concentration of stainless steel $(65 \mathrm{v} / 0)$ in the energy-absorbing compartment is effective in moderating the energetic neutrons emitted from the plasma. The gamma rays produced in inelastic neutron reactions with the nuclei of stainless steel, particularly iron, are absorbed by the stainless steel and potassium, giving rise to the large gamma-ray contribution to the nuclear heating in the energy-absorbing compartment. In the lithiumladen blanket assembly, the nuclear heating is dominated by the ${ }^{7} \operatorname{Li}\left(n, n^{\prime}, \alpha\right) T$ reaction at high energy and by the ${ }^{6} \mathrm{Li}(n, \alpha) T$ reaction which is characterized by a large $1 / \mathrm{v}$ cross section at low energy." In the blanket as sembly containing potassium as the energy absorber, the neutrons and gamma rays contribute approximately equally to the nuclear heating. 


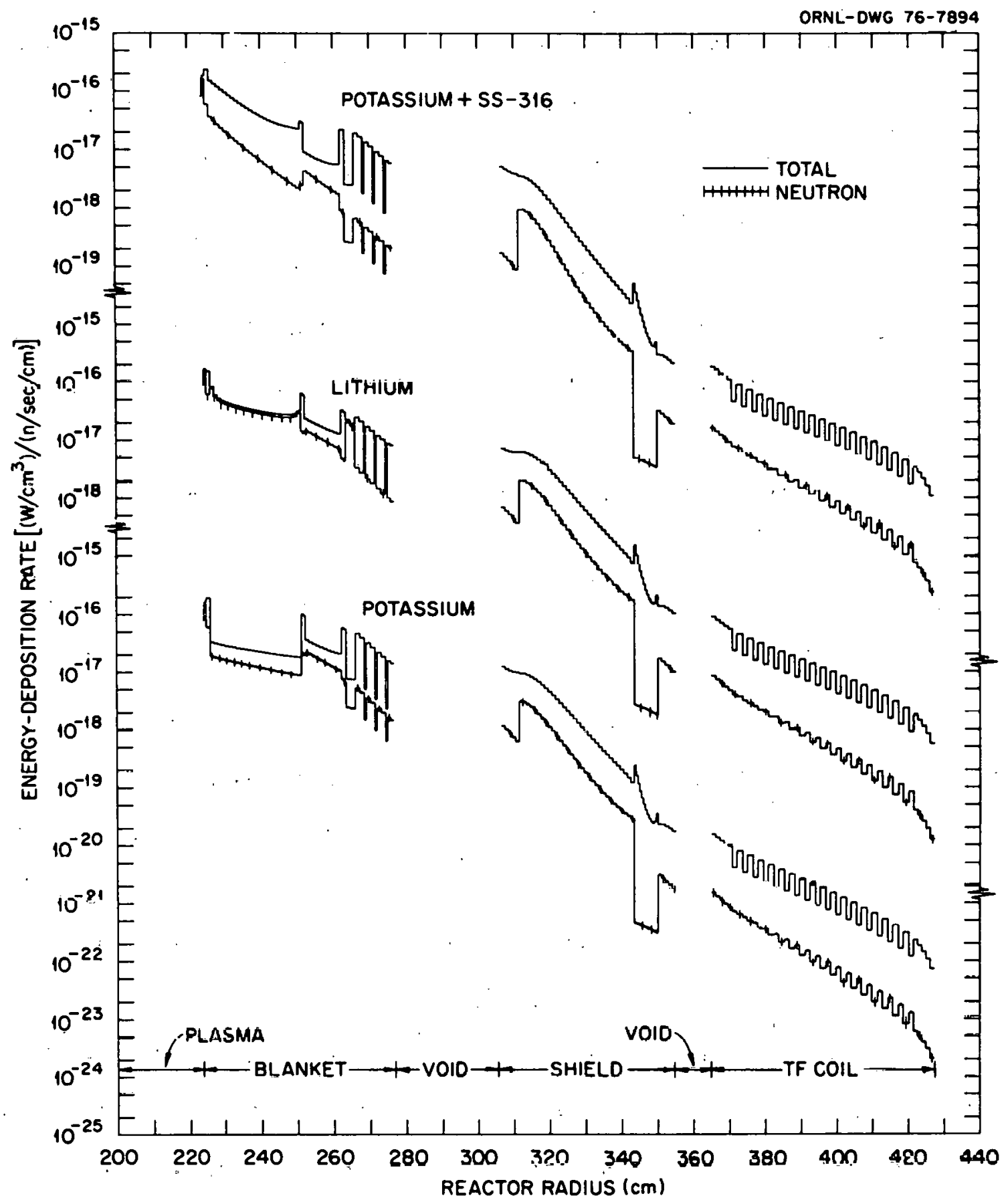

Fig. 5 Energy Deposition Rate as a Function of Reactor Radius in the Water-Cooled Reference Design Reactor When Potassium Plus SS-316, Lithium, and Potassium Only are Used as the Energy Absorber. 
The graphite reflector in each blanket extracts the kinetic energy of the 'neutrons' that leak from the energy-absorbing compartment. The neutrons are moderated by the graphite and recovered in the form of heat via $(n, \alpha)$ reactions: The gamma-ray heating is due mainly to the absorption of photons produced by neutron reactions in the graphite as well as those photons that leak from the energy-äbsorbing compartment. In the gamma-ray shield of the blanket, the structure in the curves shown in Fig. 5 indicates the heating rates in the alternating stainless-steel plates and coolant channels. The large gamma-ray heating in the plates is due to the absorption of gamma rays by the stainless steel.

$\therefore$ The shield composition and dimensions are the same for the three blanket configurations. The peak heating rate occurs at the inner edge of each shield. For a neutron wall loading of $1 \mathrm{MW} / \mathrm{m}^{2}$, the peak total heating rates are $0.31,0.43$, and $0.75 \mathrm{~W} / \mathrm{cm}^{3}$ for the potassium plus SS-316, lithium, and potassium configurations, respectively. The differences in these values are due to the relative radiation shielding effectiveness of the blanket assembly in each reactor configuration. The neutron energy leaking from the bilanket is moderated by the 5 -cm-thick stainless-steel structural member at the inner surface of the shield. The large difference between the total and neutron heating rates in this structure is due to the absorption of gamma radiation leaking "from the blanket assembly along with that produced in inelastic and neutron-capture reactions that occur in the stainless steel. The abrupt change in the neutron heating rate at the inner surface of that portion of the shield containing stainless steel $(65 \mathrm{v} / 0)$ and borated water $(35 \mathrm{v} / 0)$ is due to the absorption of low-energy neutrons by the boron leading to the exothermic ${ }^{10} B(n, \alpha)$ reaction. These reactions take place throughout 
this portion of the shield as the stainless steel further moderates the neutrons and the water thermalizes them. The large gamma-ray heating rate is due mainly to the absorption of gamma rays by the stainless steel. The heating rate in the lead liner that surrounds the shield is due almost entirely to gamma-ray absorption.

The shapes of the heating-rate curves in the TF coils are essentially the same for each configuration but differ in magnitude according to the relative shielding effectiveness of the blanket-shield combination. The peak heating rates in the TF coils for the potassium plus SS-316, lithium, and potassium only configurations correspond to $1.1 \times 10^{-4}, 5.4 \times 10^{-4}$, and $9: 3 \times 10^{-4} \mathrm{~W} / \mathrm{cm}^{3}$, respectively, for a neutron wall loading of $1 \mathrm{MW} / \mathrm{m}^{2}$.

The volume-integrated neutron, gamma-ray, and total heating rates in the various components of the reactor, as well as: the fractional total heating rate in the reactor components, are given in Table $V$ as a function of the blanket-absorber material. The total heating rate in the reactor containing potassium plus SS-316 is 1.16 times greater than that in the configuration containing lithium and 1.12 times greater than that in the assembly containing potassium only. The larger value is due primarily to the large number of exothermic $(n, \gamma)$ reactions that take place in the stainless steel in the energy-absorbing compartment. For a power-producing reactor, the larger value results in a net increase in the system power output.

For all of the configurations, $\geq 90 \%$ of the fusion energy is recovered in the form of heat in the blanket modules. The blanket modules are defined here to include all of the components of the reactor except the shield and the TF coil assemblies. In the reactor containing potassium plus SS-316, $\sim 97 \%$ of the available neutron and secondary gamma-ray energy. is recovered 
Table $V$. Voljme-integraled neutron and gamma-ray contributions to the nuclear heating rate in the water-cooled reference design reactor as a function of blanket absorber material

\begin{tabular}{|c|c|c|c|c|c|c|c|c|c|c|c|c|}
\hline \multirow{4}{*}{ Reactor componen-s } & \multicolumn{12}{|c|}{ Absorber material } \\
\hline & \multicolumn{4}{|c|}{$K+S S-: 16$} & \multicolumn{4}{|c|}{$\dot{L i}$} & \multicolumn{4}{|c|}{$\mathbf{K}$} \\
\hline & $\begin{array}{c}\text { Neutron } \\
\text { heating } \\
\text { rate }\end{array}$ & $\begin{array}{c}\text { Gamma-fay } \\
\text { heating } \\
\text { - rale }\end{array}$ & $\begin{array}{c}\text { Total } \\
\text { heating } \\
\text { rate }\end{array}$ & $\begin{array}{c}\text { Fractional } \\
\text { heating } \\
\text { rate } \\
\end{array}$ & $\begin{array}{l}\text { Neut:on } \\
\text { heating } \\
\text { rate } \\
\end{array}$ & $\begin{array}{c}\text { Gamma-ray } \\
\text {, heating } \\
\text { rate }\end{array}$ & $\begin{array}{l}\text { Total } \\
\text { heating } \\
\text { rate } \\
\end{array}$ & $\begin{array}{c}\text { Fractional } \\
\text { heating } \\
\text { rate } \\
\end{array}$ & $\begin{array}{l}\text { Neutron } \\
\text { heating } \\
\text { rate }\end{array}$ & $\begin{array}{c}\text { Gamma ray } \\
\text { : heating } \\
\text { rate }\end{array}$ & $\begin{array}{c}\text { Total } \\
\text { heating } \\
\text { rate }\end{array}$ & $\begin{array}{l}\text { Fractional } \\
\text { heating } \\
\text { rate } \\
\end{array}$ \\
\hline & & $(w / n ; s e c)$ & & $(\%)$ & & $(w / n / \mathrm{sec})$ & & (\%) & & $(w / n / s e c)$ & & (7) \\
\hline Graphite curtain & $3.56 \times 10^{-14}$ & $9.30 \times 10^{-15}$ & $4.49 \times 10^{-14}$ & 1.41 & $3.41 \times 10^{-14}$ & $8.22 \times 10^{-15}$ & $4.23 \times 10^{-14}$ & 1.55 & $3.35 \times 10^{-14}$ & $1.21 \times 10^{-14}$ & $4.56 \times 10^{-14}$ & 1.61 \\
\hline Water coolant & $1.48 \times 10^{-13}$ & $2.12 \times 10^{-14}$ & $1.69 \times 10^{-13}$ & 5.31 & $1.40 \times 10^{-13}$ & $1.07 \times 10^{-14}$ & $1.51 \times 10^{-13}$ & 5.52 & $1.33 \times 10^{-13}$ & $1.70 \times 10^{-14}$ & $1.50 \times 10^{-13}$ & 5.30 \\
\hline \multicolumn{13}{|c|}{ 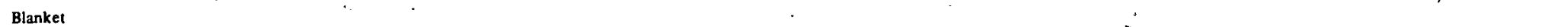 } \\
\hline First structural wall & $9.28 \times 10^{-14}$ & $2.85 \times 10^{-13}$ & $3.78 \times 10^{-13}$ & $\vdots 1.88$ & $9.49 \times 10^{-14}$ & $1.43 \times 10^{-13}$ & $2.38 \times 10^{-13}$ & 8.72 & $9.17 \times 10^{-14}$ & $2.13 \times 10^{-13}$ & $3.05 \times 10^{-13}$ & 10.78 \\
\hline Absorber compartment & $4.12 \times 10^{-13}$ & $2.69 \times 10^{-12}$ & $2.10 \times 10^{-12}$ & 66.02 & $1.24 \times 10^{-12}$ & $1.14 \times 10^{-13}$ & $1.35 \times 10^{-12}$ & 49.59 & $4.69 \times 10^{-13}$ & $4.02 \times 10^{-13}$ & $8.71 \times 10^{-13}$ & 30.79 \\
\hline Reflector $^{a}$ & $499 \times 10^{-14}$ & $1.48 \times 10^{-13}$ & $1.98 \times 10^{-13}$ & 6.22 & $1.92 \times 10^{-13}$ & $2.37 \times 10^{-13}$ & $4.29 \times 10^{-13}$ & 15.72 & $296 \times 10^{-13}$ & $4.07 \times 10^{-13}$ & $7.03 \times 10^{-13}$ & 24.84 \\
\hline Gamma-ray shielo & $6.80 \times 10^{-15}$ & $1.85 \times 10^{-13}$ & $1.92 \times 10^{-13}$ & 6.04 & $1.23 \times 10^{-13}$ & $2.12 \times 10^{-13}$ & $3.35 \times 10^{-13}$ & 12.27 & $600 \times 10^{-14}$ & $4.09 \times 10^{-13}$ & $4.69 \times 10^{-13}$ & 16.56 \\
\hline Shield & $1.44 \times 10^{-14}$ & $8.47 \times 10^{-14}$ & $9.91 \times 10^{-14}$ & 3.12 & $3.64 \times 10^{-14}$ & $1.44 \times 10^{-13}$ & $1.80 \times 10^{-13}$ & 6.61 & $5.69 \times 10^{-14}$ & $2.27 \times 10^{-13}$ & $2.84 \times 10^{-13}$ & 10.03 \\
\hline \multicolumn{13}{|l|}{ TF coil } \\
\hline SS-316 structure & $1.62 \times 10^{-18}$ & $1.71 \times 10^{-17}$ & $1.87 \times 10^{-17}$ & $5.8 \times 10^{-4}$ & $8.43 \times 10^{-18}$ & $8.36 \times 10^{-17}$ & $9.20 \times 10^{-17}$ & $3.3 \times 10^{-3}$ & $1.51 \times 10^{-17}$ & $1.46 \times 10^{-16}$ & $1.61 \times 10^{-16}$ & $5.7 \times 10^{-3}$ \\
\hline TF coil windings , & $2.29 \times 10^{-18}$ & $2.59 \times 10^{-17}$ & $2.82 \times 10^{-17}$ & $8.9 \times 10^{-4}$ & $1.20 \times 10^{-17}$ & $1.33 \times 10^{-16}$ & $1.45 \times 10^{-16}$ & $5.3 \times 1.0^{-3}$ & $207 \times 10^{-17}$ & $2.26 \times 10^{-16}$ & $2.46 \times 10^{-1.6}$ & $8.7 \times 10^{-3}$ \\
\hline SS-316 structure & $7.55 \times 10^{-21}$ & $3.26 \times 10^{-19}$ & $3.34 \times 10^{-19}$ & $1.0 \times 10^{-5}$ & $3.99 \times 10^{-20}$ & $1.72 \times 10^{-18}$. & $1.76 \times 10^{-18}$ & $6.45 \times 10^{-5}$ & $6.12 \times 10^{-20}$ & $2.20 \times 10^{-18}$ & $2.26 \times 10^{-18}$ & $8.0 \times 10^{-5}$ \\
\hline Total heating rate & $7.60 \times 10^{-13}$ & $2.42 \times 10^{-12}$ & $3.18 \times 10^{-12}$ & & $1.86 \times 10^{-12}$ & $8.65 \times 10^{-13}$ & $2.73 \times 10^{-12}$ & & $1.15 \times 10^{-12}$ & $1.68 \times 10^{-12}$ & $2.83 \times 10^{-12}$ & \\
\hline Mev per neutrón & 4.74 & 15.10 & 19.84 & & 11.67 & 5.37 & 17.04 & & $\pi .18$ & 10.48 & 17.66 & . \\
\hline
\end{tabular}

Includes SS-31e, on the ianer and outer radial surfaces. 
as heat in the blanket assembly compared to $\sim 93 \%$ for the configuration containing potassium. In each reactor design, the shield recovers nearly all of the remaining neutron and secondary gamma-ray energy in the form of heat. The small fraction of the remaining energy that leaks from the shield is deposited in the TF coils. It is interesting to note that the ratio of the volume-integrated gamma-ray heating rate to the volume-integrated neutron-heating rate in the TF coil windings is essentially the same ( $11: 1$ ) in each configuratiun. The fractional heating rate in the TF coil windings in the reactor containing potassium plus SS-316 of $8.9 \times 10^{-4} \%$ is. a factor of six lower than the fractional heating rate in the TF coils in. the reactor containing 1 ithium and a factor of $\sim 10$ smaller than in the TF coils in the reactor containing potassium as the energy absorber.

The nuclear heating rates as a function of radius in the reference-design reactor without water cooling of the first structural wall (see Table I) exhibit essentially the same behavior as the heating rates as shown in Fig. 5 The spatial distributions of the nuclear heating were calculated for the reactor configurations when potassium plus SS-316 and lithium were used as the energy-absorbing material in the blanket assembly. The heating rate in the SS-316 first structural wall for a neutron wall loading of $1 \mathrm{MW} / \mathrm{m}^{2}$ is $12.4 \mathrm{~W} / \mathrm{cm}^{3}$ for the configuration containing potassium plus SS-316 and $9.5 \mathrm{~W} / \mathrm{cm}^{3}$ when lithium is the energy-absorbing material. The differences between these heating rates and those given above for the same energyabsorbing material can be ascribed to the exclusion of the water-filled cooling channel. The presence of the water leads to a reduction in energy of the plasma neutrons as a result of neutron collisions with the hydrogen nuclei in the water. 
The peak heating rates at the inner surfaces of the shield and the TF coil assembly are 0.43 and $1.2 \times 10^{-4} \mathrm{~W} / \mathrm{cm}^{3}$, respectively, for the potassium plus SS-316 case and 0.48 and $5.7 \times 10^{-4} \mathrm{~W} / \mathrm{cm}^{3}$, respectively, in the reactor configuration containing lithium. All of these values are higher than those obtained at the same locations in the water-cooled reference-design reactor. The shift in the energy distribution of the neutrons as a result of the inclusion of the water leads to lower peak heating rates, particularly in the cryogenic TF coil assembly where temperature increases due to nuclear heating are costly to overcome. It is generally asserted that $\sim 500 \mathrm{~W}$ of refrigeration power are required to overcome the temperature rise for an energy deposition rate of $1 \mathrm{~W}$.

The volume-integrated neutron, gamma-ray, and total heating rates, and the fractional total heating rates are summarized in Table VI as a function of the energy-absorbing material for the reference-design reactor (without water cooling). In both configurations $>90 \%$ of the energy is recovered in the form of heat in the blanket assembly. The shield recovers all but a small fraction of the remaining energy. The integral rate in the TF coll windings is a factor of $\sim 6$ smaller in the potassium plus SS-316 case than In the lithium case.

The nuclear heating rate as a function of reactor radius in the reference reactor with sodium hydroxide as the first wall and blanket coolant is shown in Fig. 6 when 1 ithium is used as the energy-absorbing material in the blanket assembly. The solid curves show the total heating rate and the curves bearing tick marks show the heating rate due to neutrons only. The peak heating rates in the sodium-hydroxide-filled cooling channel adjacent to the first SS-316 structural wall and in the wall itself for a 
Table V1. Volume--ntegrated neutron and gamma-ray contributions to the heating rate in the re:erence design reactor as a function of absorber material

\begin{tabular}{|c|c|c|c|c|c|c|c|c|}
\hline \multirow{4}{*}{ Reactor components } & \multicolumn{8}{|c|}{ Absorber material } \\
\hline & \multicolumn{4}{|c|}{$K+\$ S-316$} & \multicolumn{4}{|c|}{$\mathrm{Li}$} \\
\hline & $\begin{array}{l}\text { Neutron } \\
\text { hea:ing } \\
\text { rate }\end{array}$ & $\begin{array}{c}\text { Gamma-ray } \\
\text { heating } \\
\text { rate }\end{array}$ & $\begin{array}{c}\text { Total } \\
\text { heating } \\
\text { rate }\end{array}$ & $\begin{array}{c}\text { Fractional } \\
\text { heating } \\
\text { rate }\end{array}$ & $\begin{array}{c}\text { Neution } \\
\text { heating } \\
\text { rati }\end{array}$ & $\begin{array}{c}\text { Gamma-ray } \\
\text { heating } \\
\text { rate }\end{array}$ & $\begin{array}{c}\text { Total. } \\
\text { heating } \\
\text { rate }\end{array}$ & $\begin{array}{c}\text { Fractional } \\
\text { heating } \\
\text { rate }\end{array}$ \\
\hline & . & $(w / n / \sec )$ & & (\%) & . & $(w / n / \sec )$ & & (\%) \\
\hline $\begin{array}{l}\text { Graphite curtain } \\
\text { Blanket }\end{array}$ & $3.82 \times 10^{-14}$ & $1.16 \times 10^{-14}$ & $4.98 \times 10^{-14}$ & 1.56 & $3.58 \times 10^{-14}$ & $1.90 \times 10^{-15}$ & $4.37 \times 10^{-14}$ & 1.61 \\
\hline First structural wall & $1.05 \times 10^{-13}$ & $2.09 \times 10^{-.3}$ & $3.14 \times 10^{-13}$ & 9.81 & $1.06 \times 10^{-13}$ & $1.52 \times 10^{-13}$ & $2.38 \times 10^{-13}$ & 8.78 \\
\hline Absorber compartment & $4.57 \times 10^{-13}$ & $1.70 \times 10^{-2}$ & $2.16 \times 10^{-12}$ & 67.5 & $1.28 \times 10^{-12}$ & $1.20 \times 10^{-13}$ & $1.40 \times 10^{-12}$ & 51.66 \\
\hline Reflector ${ }^{a}$ & $5.89 \times 10^{-14}$ & $2.11 \times 10^{-2.3}$ & $2.70 \times 10^{-13}$ & 8.44 & $2.08 \times 10^{-13}$ & $2.42 \times 10^{-13}$ & $4.50 \times 10^{-13}$ & 16.61 \\
\hline Gamma-ray shield & $2.21 \times 10^{-15}$ & $2.73 \times 10^{-13}$ & $2.75 \times 10^{-13}$ & 8.59 & $1.55 \times 10^{-13}$ & $2.26 \times 10^{-13}$ & $3.81 \times 10^{-13}$ & 14.06 \\
\hline Shield & $1.75 \times 10^{-14}$ & $1.13 \times 10^{-13}$ & $1.31 \times 10^{-13}$ & 4.09 & $3.97 \times 10^{-14}$ & $1.59 \times 10^{-13}$ & $1.99 \times 10^{-13}$ & 7.34 \\
\hline \multicolumn{9}{|l|}{ TF Coil } \\
\hline SS-316 structure & $1.72 \times 0^{-18}$ & $1.84 \times 10^{-1} ?$ & $2.01 \times 10^{-17}$ & $6.3 \times 10^{-4}$ & $.8 .97 \times 10^{-18}$ & $8.88 \times 10^{-17}$ & $9.78 \times 10^{-17}$ & $3.6 \times 10^{-3}$ \\
\hline TF Coil windings & $2.44 \times 10^{-18}$ & $2.78 \times 10^{-17}$ & $3.02 \times 10^{-17}$. & $9.4 \times 10^{-4}$ & $1.28 \times 10^{-17}$ & $1.41 \times 10^{-16}$ & $1.54 \times 10^{-16}$ & $5.7 \times 10^{-3}$ \\
\hline SS-316 structure & $8.00 \times 10^{-21}$ & $3.47 \times 10^{-1.9}$ & $3.55 \times 10^{-19}$ & $1.1 \times 10^{-5}$ & $4.24 \times 10^{-20}$ & $1.82 \times 10^{-18}$ & $1.86 \times 10^{-18}$ & $6.9 \times 10^{-5}$ \\
\hline Total heating rate & $6.79 \times 10^{-13}$ & $2.52 \times 10^{-12}$ & $3.20 \times 10^{-12}$ & & $1.82 \times 10^{-12}$ & $8.87 \times 10^{-13}$ & $2.71 \times 10^{-12}$ & \\
\hline $\mathrm{MeV}$ per neutron & 4.24 & 15.72 & 19.96 & & 11.36 & 5.54 & 16.90 & \\
\hline
\end{tabular}

${ }^{a}$ Includes SS-316 on the inner and. outer radial surfaces. 


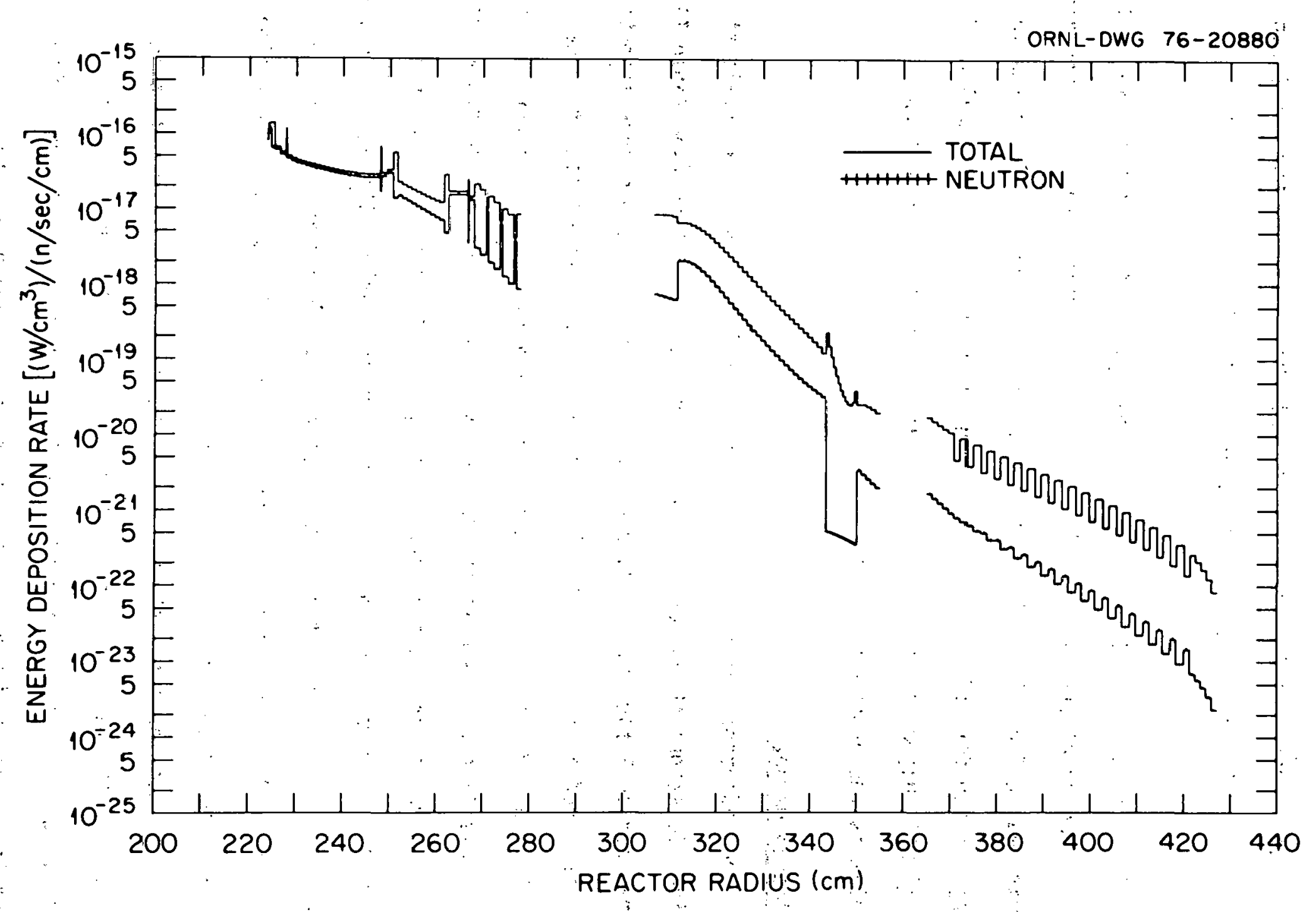

$\underline{\omega}$

Fig. 6 Energy Deposition Rate Versus Reactor Radius in the Sodium Hydroxide-Cooled Reference Design Reactor with Lithium as :he Energy Absorbing Material. 
neutron wall loading of $1 \mathrm{MW} / \mathrm{m}^{2}$ are 8.5 and $8.7 \mathrm{~W} / \mathrm{cm}^{3}$, respectively. The peak heating rates at the inner surface of the shield and the first conductor layer in the TF coil assembly are 0.53 and $2.8 \times 10^{-4} \mathrm{~W} / \mathrm{cm}^{3}$, respectively.

The volume-integrated neutron, garma-ray, and total heating rates in the components of the reactor along with the fractional heating rates are summarized in Table VII. The blanket assembly recovers $>90 \%$ of the fusion energy in the form of heat. The total heating rate in the TF coil windings is slightly higher in this design than in the two previous designs when iithium is the absorbing material.

\section{Radiation Damage}

The radiation damage induced in the SS-316 structural materials at various locations throughout the reference-design reactors (see Table I) are summarized in Tables VIII, IX, and $X$ as a function of the energy-absorbing material used in the blanket. These data have been normalized to a neutron wall loading of $1 \mathrm{MW} / \mathrm{m}^{2}$. The radiation damage is compared in terms of the atomic displacement rate in displacements per atom per year in Table VIII and in terms of the hydrogen and helium gas production rates in atom parts per million per year in Tables $I X$ and $X$, respectively. The gas-production rates take into account the hydrogen production from the $(n, p)$ and $\left(n, n^{\prime}\right) p$ reactions and the helium production from the $(n, \alpha)$ and $\left(n, n^{\prime}\right) \alpha$ reactions that take place in the stainless steel.

of particular interest in fusion-reactor design is the radiation damage that occurs in the first structural wall in the reactor. This structure is nearest to the harsh neutron environment of the plasma, and the maintenance schedule and related problems are based on the damage rate to this component 
Table VII. Volume-integrated neutron and gamma-ray heating rates in the sodium-hydroxide-cooled reference design reactor

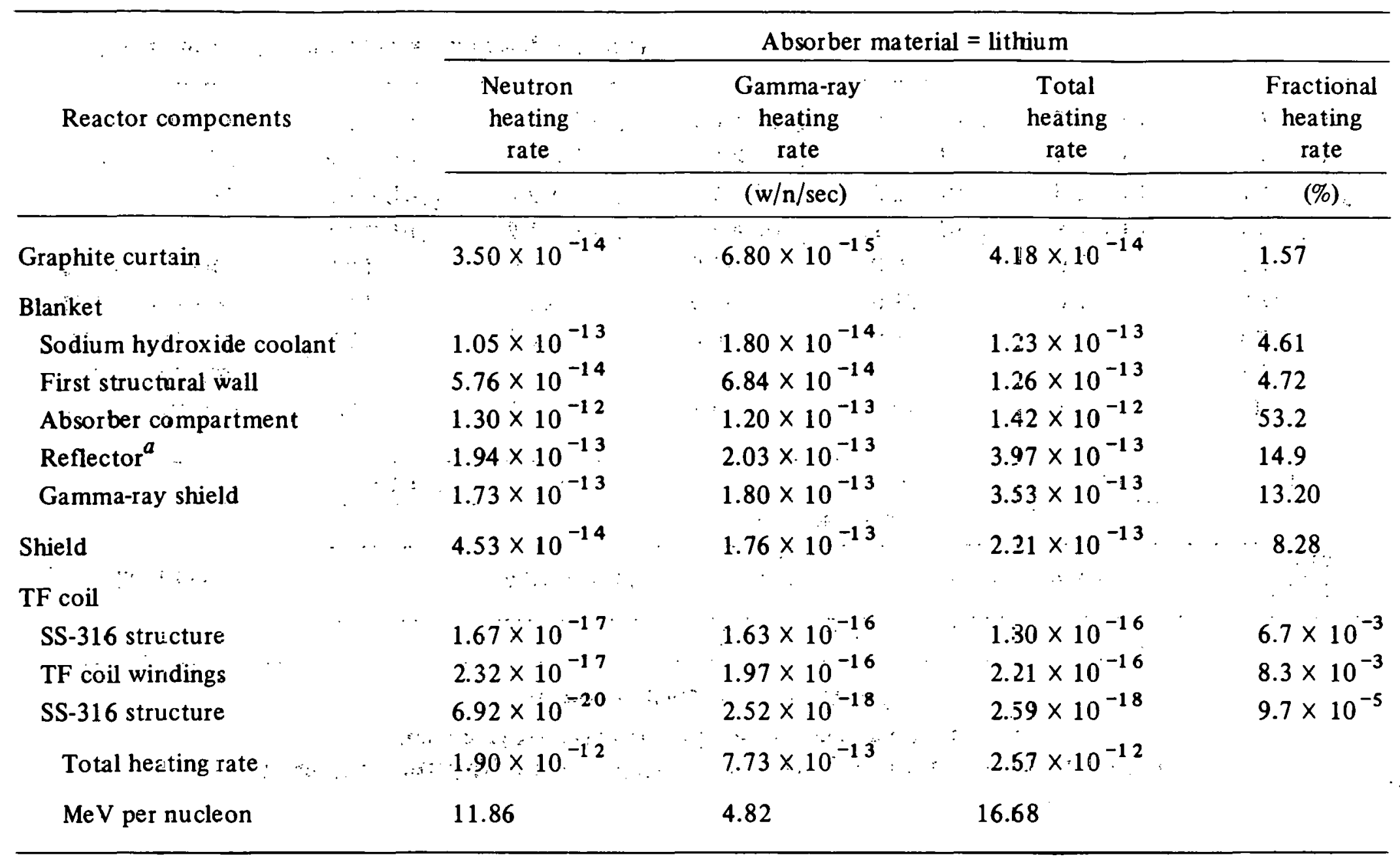

${ }^{a}$ Includes SS-316 structure on the inner and outer radial surfaces. 
Table VIII. Spatial dependences of the displacements per atom per year in the SS-316 structure at various locations in the reference reactor designs ${ }^{a}$

(Neutron wall loading $=1.0 \mathrm{MW} / \mathrm{M}^{2}$ )

\begin{tabular}{|c|c|c|c|c|c|c|}
\hline \multirow{4}{*}{ Location } & \multicolumn{6}{|c|}{ Reference reactor design } \\
\hline & \multicolumn{3}{|c|}{ Water cooled } & \multicolumn{2}{|c|}{ Without cooling } & \multirow[t]{2}{*}{$\begin{array}{l}\mathrm{NaOH} \\
\text { cooled }\end{array}$} \\
\hline & \multicolumn{5}{|c|}{ Absorber material } & \\
\hline & $\mathbf{K}+$ SS -316 & $\mathbf{L i}$ & $\mathrm{K}$ & $K+S S-316$ & $\mathrm{Li}$ & $\mathbf{L i}$ \\
\hline First structural wall & 10.9 & 10.7 & 10.1 & 13.5 & 12.2 & 11.3 \\
\hline Rear of absorber & 1.2 & 3.3 & 4.7 & .1 .5 & $3: 8$ & 4.1 \\
\hline Rear of reflector & 0.39 & -1.3 & 2.0 & 0.46 & $1.5:$ & 1.4 \\
\hline Rear of blanket & 0.13 & C.38 & 0.58 & 0.15 & 0.42 & 0.31 \\
\hline Front of shield & 0.08 & 6.23 & 0.38 & 0.09 & 0.26 & 0.25 \\
\hline Rear of shield & $1.2 \times 10^{-4}$ & $6.1 \times 10^{-4}$ & $1.1 \times 10^{-3}$ & $1.3 \times 10^{-4}$ & $6.8 \times 10^{-4}$ & $1.0 \times 10^{-3}$ \\
\hline Front of $\mathrm{TF}$ coil & $7.3 \times 10^{-5}$ & $3.6 \times 10^{-4}$ & $4.6 \times 10^{-4}$ & $7.7 \times 10^{-5}$ & $6.8 \times 10^{-4}$ & $7.3 \times 10^{-4}$ \\
\hline Center of TF coil & $9.5 \times 10^{-6}$ & $5.1 \times 10^{-5}$ & $5.5 \times 10^{-5}$ & $1.0 \times 10^{-5}$ & $6.7 \times 10^{-5}$ & $1.1 \times 10^{-4}$ \\
\hline Rear of TF coil & $5.4 \times 10^{-7}$ & $2.3 \times 10^{-6}$ & $4.0 \times 10^{-6}$ & $5.7 \times 10^{-7}$ & $3.0 \times 10^{-6}$ & $4.7 \times 10^{-6}$ \\
\hline
\end{tabular}

${ }^{a}$ Based on an effective displacement energy: of $40 \mathrm{eV}$. 
Table IX. Spatial dependences of the hydrogen gas production rate (appm/year) in the SS-316 structure at yarious locations in the reference reactor designs

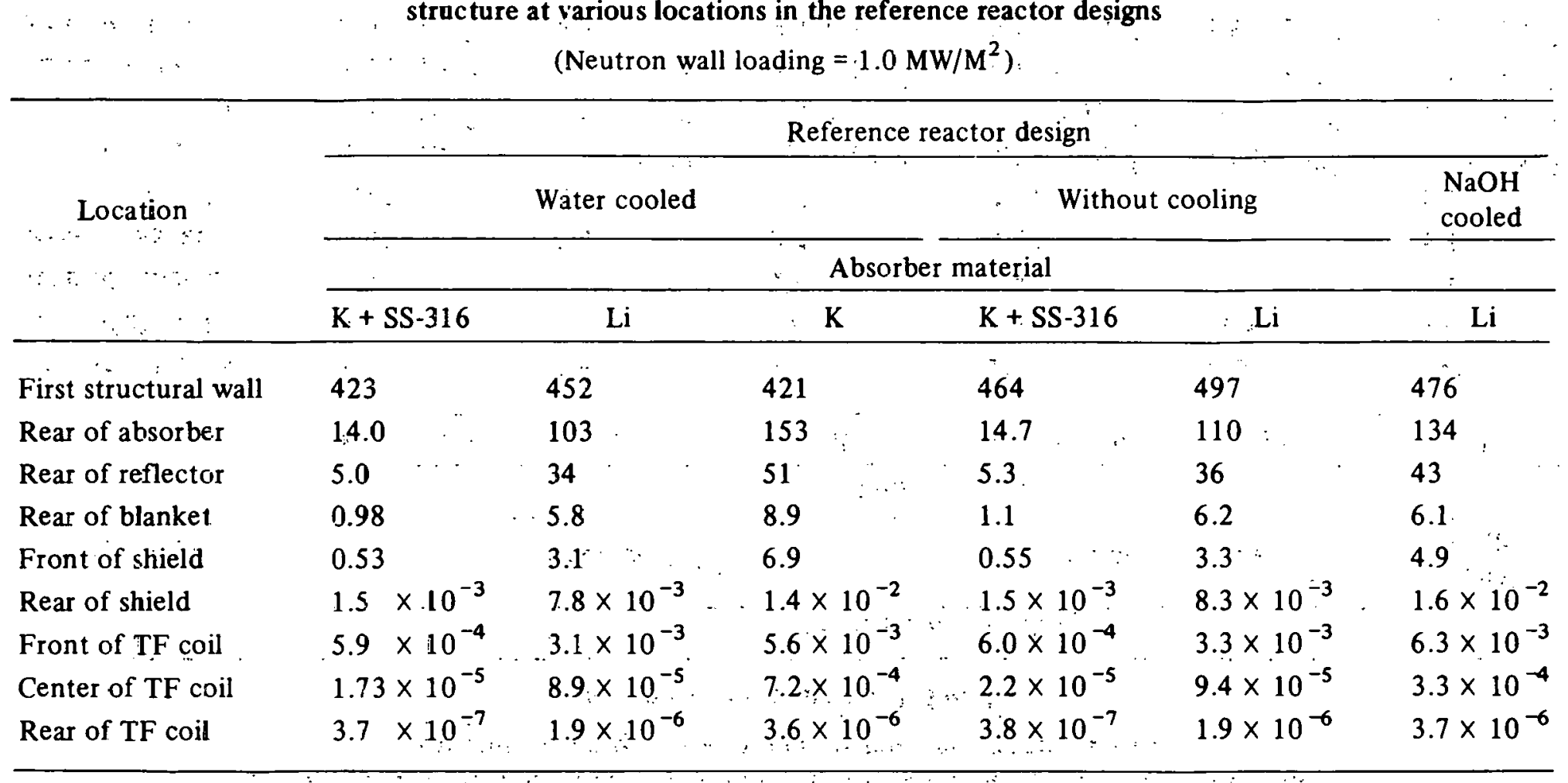


Table X. Spatial dependences of the helium gas-production rate (appm/year) in the SS-316 structure at various locations in the reference reactor designs

(Neutron wall loading $=1.0 \mathrm{MW} / \mathrm{M}^{2}$ )

\begin{tabular}{|c|c|c|c|c|c|c|}
\hline \multirow{4}{*}{ Location } & \multicolumn{6}{|c|}{ Reference reactor cesign } \\
\hline & \multicolumn{3}{|c|}{ Fater sooled } & \multicolumn{2}{|c|}{ Without cooling } & \multirow[t]{2}{*}{$\begin{array}{l}\mathrm{NaOH} \\
\text { cooled }\end{array}$} \\
\hline & \multicolumn{5}{|c|}{ Absorber material } & \\
\hline & $k+S S-316$ & $\mathbf{L i}$ & $\mathbf{K}$ & $\mathrm{K}+\mathrm{SS}-316$ & $\mathbf{L i}$ & $\mathrm{Li}$ \\
\hline First structural wall & 129 & 134 & 129 & 142 & 148 & 141 \\
\hline Rear of absorber & 3.7 & 28 & 41 & 3.9 & 29.5 & 36 \\
\hline Rear of reflector & 1.3 & 8.8 & 13 & 1.4 & 9.3 & 9.4 \\
\hline Rear of blanket & 0.25 & 1.5 & 2.4 & 0.27 & 1.6 & 1.5 \\
\hline Front of shield & 0.13 & 0.8 & 1.3 & 0.14 & 0.82 & 1.2 \\
\hline Rear of shield & $3.7 \times 10^{-4}$ & $1.9 \times 10^{-3}$ & $3.5 \times 10^{-3}$ & $3.7 \times 10^{-4}$ & $2.1 \times 10^{-3}$ & $3.8 \times 10^{-3}$ \\
\hline Front of TF coil & $1.5 \times 10^{-4}$ & $7.5 \times 10^{-4}$ & $1.4 \times 10^{-3}$ & $1.5 \times 10^{-4}$ & $7.9 \times 10^{-4}$ & $1.5 \times 10^{-3}$ \\
\hline Center of TF coil & $4.2 \times 10^{-6}$ & $20 \times 10^{-5}$ & $4.1 \times 10^{-5}$ & $4.4 \times 10^{-6}$ & $2.1 \times 10^{-5}$ & $7.5 \times 10^{-5}$ \\
\hline Rear of TF coil & $8.9 \times 10^{-8}$ & $4.3 \times 10^{-7}$ & $8.7 \times 10^{-7}$ & $9.12 \times 10^{-8}$ & $4.6 \times 10^{-7}$ & $8.4 \times 10^{-7}$ \\
\hline
\end{tabular}


of the reactor. In general, less damage is incurred in the first wall of the reactor design with water cooling than in the design without water cooling or when sodium hydroxide is used as the coolant. The neutrons emitted from the plasma are degraded in energy as they pass through the 0.64-cm-thick water-cooling channel as the result of scattering from hydrogen nuclei. The atomic displacement and gas-production cross sections are each peaked at high: $(\sim 14 \mathrm{MeV})$ neutron energy, and the reduction in the intensity of energetic neutrons resulting from these collisions leads

As shown in Table VII, the atomic-displacement rate in the first-wall in the reactor design using potassium plus SS-316 as the absorber material is $\sim 20 \%$ smaller in the water-cooled design than in the configuration without water cooling. When lithium is used as the absorber, the atomic-displacement rate is $\sim 12 \%$ lower in the water-cooled design than in the design without water cooling and $\sim 5 \%$ lower than in the design using sodium hydroxide as the coolant.

The hydrogen and helium gas-production rates in the first wall follow essentially the same trend as the atomic-displacement rate as shown in Tables IX and $X$. The differences in the data in each design may be attributed to the degradation of the high-energy neutron intensity due to the presence of the water- or sodium-hydroxide-cooling channels.

For a given design, some of the differences in the first-wall radiation damage as a function of the absorber material can be attributed to neutrons backscattered from the absorber material. These differences may be noted in the water-cooled design and in the design without cooling when potassium plus SS-316 and lithium are used as the absorber. 
The radiation damage induced in the SS-316 structural components elsewhere in the reference-design reactor assemblies is also summarized in Tables VIII, IX, and $X$. The extent of the damage induced in these components depends strongly on the energy-absorbing material in the blanket. The atomic-displacement and gas-production rates in the stainless steel behind the potassium-plus SS-316-filled blanket are considerably smaller than in the structure behind the lithium- and potassium-filled blankets. The stainless. steel in this blanket moderates the neutrons in energy more rapidly than in the other absorber materials. The small differences in the damage values in the structure behind the potassium plus SS-316 or lithium-filled abosrber compartments compared as a function of the first-wall cooling scheme are due to the differences in the neutron spectra that result from the presence or exclusion of coolant.

The spatial distributions of the atomic displacement, and the hydrogen and helium gas production rates in the aluminum, copper, and niobium in the conductors in the TF coil are shown in Figs. 7, 8, and 9, respectively. These results were obtained for the water-cooled reference reactor and are compared as a function of the energy absorbing material used in the blanket. The data are normalized to a neutron wall loading of $1 \mathrm{MW} / \mathrm{m}^{2}$.

The results in each figure exhibit the same behavior as a function of the energy absorber. The radiation damage to the coil in the configuration containing potassium plus SS-316 is smaller than in the configurations that use potassium only or lithium as the absorber. 


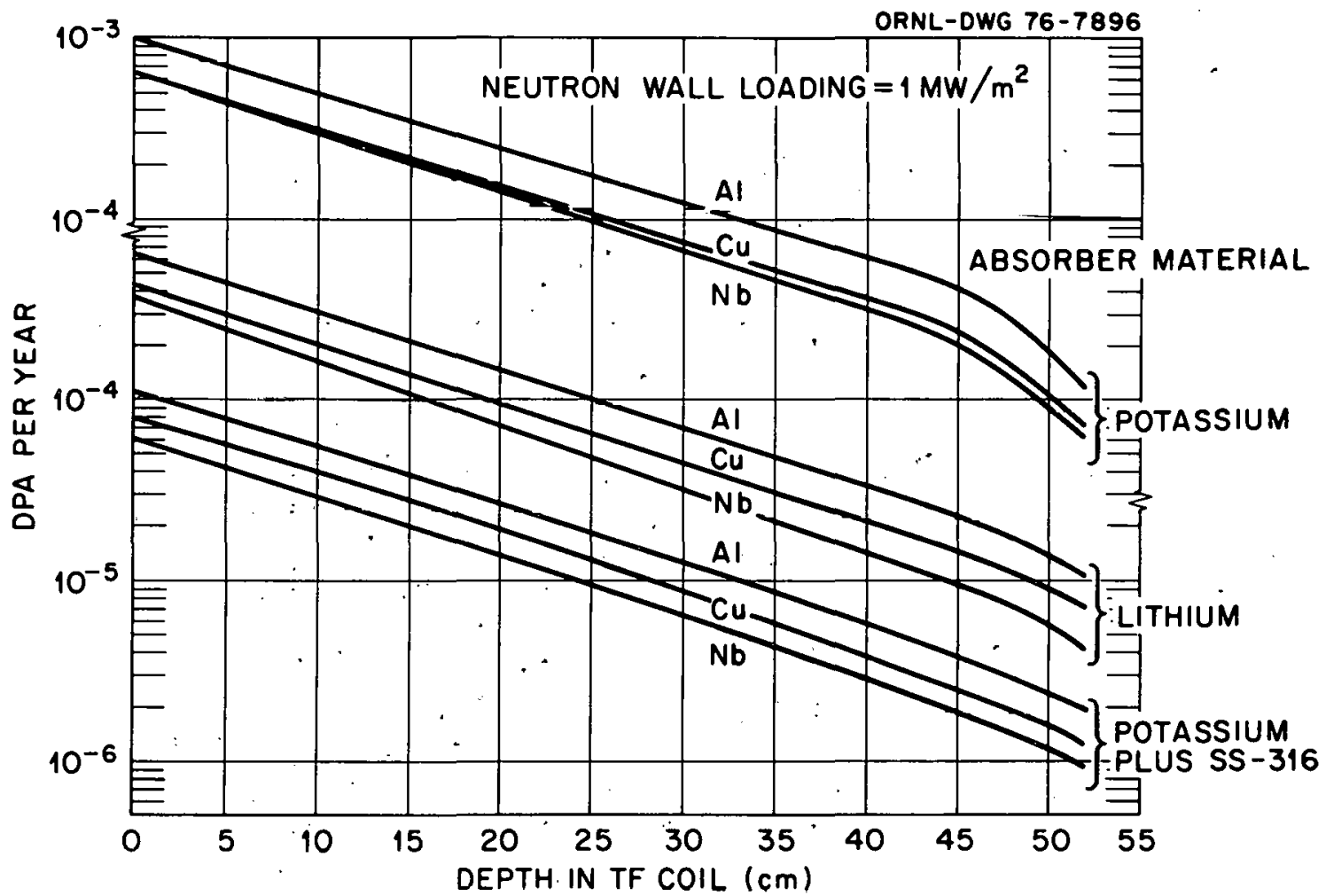

Fig. 7 Atomic Displacement Rate as a Function of Depth in the TF Coil and of Absorber Material in the Water-Cooled Reference Design Reactor. 


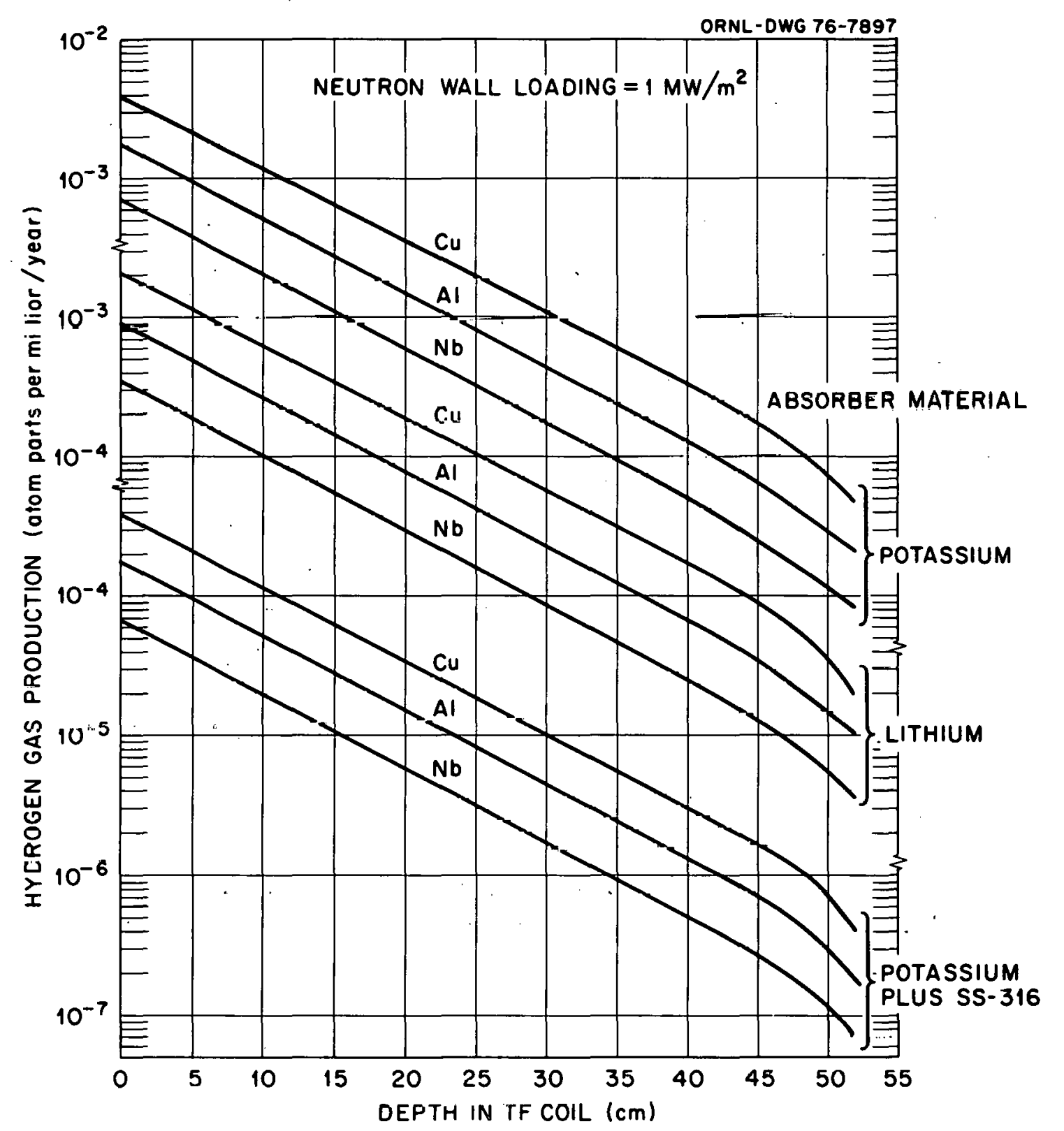

Fig. 8 Hydrogen Gas Production Rate as a Function of Depth in the TF Coil and of Absorber Material in the Water-Cooled Reference Design Reactor. 


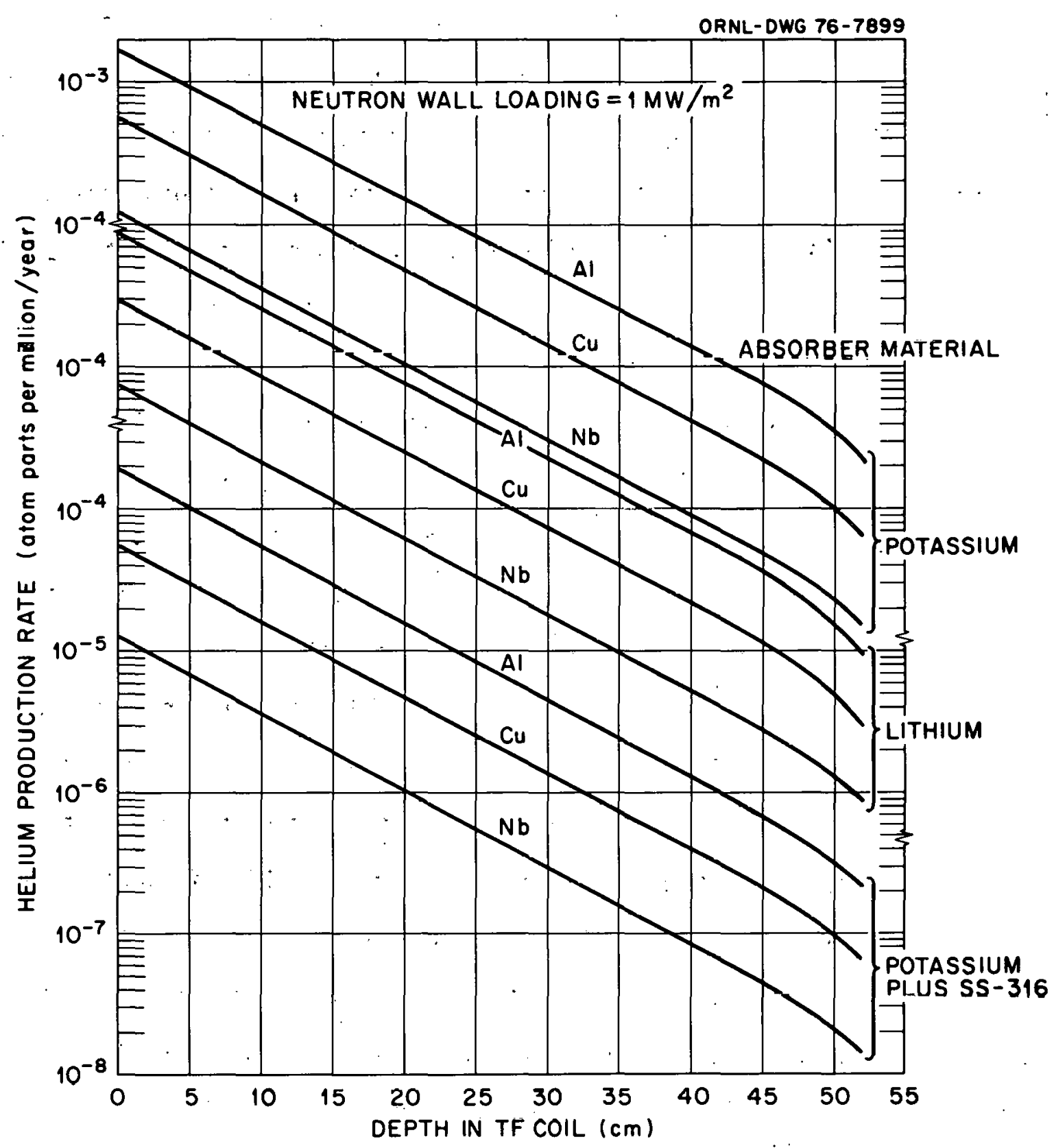

Fig. 9 Helium Gas Production Rate as a Function of Depth in the TF Coil and of Absorber Material in the Water-Cooled Reference Design Reactor. 


\section{Tritium Breeding}

The design criteria for the EPR specified that tritium breeding be demonstrated in a few experimental blanket modules. The calculations to determine tritium breeding in the various reference designs were carried out using natural lithium as the fertile material with breeding being accomplished via the ${ }^{6} \mathrm{Li}(n, \alpha) T$ and the ${ }^{7} \mathrm{Li}\left(n, n^{\prime} \alpha\right) T$ reactions. The ${ }^{6} \mathrm{Li}$ reaction is exothermic and is characterized by a large thermal cross section $(\sim 950$ b) that varies as $1 / \mathrm{V}$ and by a large resonance at $\sim 0.25 \mathrm{MeV}$. The ${ }^{7} \mathrm{Li}$ reaction has a threshold at $\sim 2.5 \mathrm{MeV}$ and peaks to $\sim 425 \mathrm{mb}$ at $8 \mathrm{MeV}$.

The tritium breeding ratios in the three reactor designs described above are compared in Table XI. Successful breeding $(>1)$ is achieved in each design with $\sim 85 \%$ of the total tritium production taking place in the primary lithium region (i.e., the energy absorbing compartment) in the blanket. Neutron reactions in $6 \mathrm{Li}$ account for $\sim 60 \%$ of the breeding. In the water-cooled design, the number of tritium nuclei per incident neutron produced in the ${ }^{6} \mathrm{Li}$. in the primary lithium region $(0.623)$ is larger than in the design with no cooling $(0.603)$ or when sodium hydroxide is the first-wall coolant (0.607). The difference is due to the presence of the water which reduces the energy of the neutrons incident on the lithium from the plasma and also thermalizes low-energy neutrons that backscatter from the lithium. The total breeding in the primary lithium compartment is, however, essentially the same in each blanket and is due to the compensating neutron reactions in ${ }^{7} \mathrm{Li}$. 
Table XI. Tritium breeding in the EPR reference reactor designs

\begin{tabular}{|c|c|c|c|c|c|c|c|c|c|c|c|c|}
\hline \multirow{3}{*}{$\begin{array}{l}\text { Reference design } \\
\text { zone }\end{array}$} & \multirow{3}{*}{$\begin{array}{c}\text { Thickness } \\
(\mathrm{cm})\end{array}$} & \multicolumn{3}{|c|}{ Water-cooled } & \multicolumn{3}{|c|}{ No cooling } & \multirow{3}{*}{ Zone } & \multirow{3}{*}{$\begin{array}{l}\text { Thickness } \\
\text { (cm) }\end{array}$} & \multicolumn{3}{|c|}{ Sodium-hydroxide cooled } \\
\hline & & ${ }^{6} \mathrm{Li}$ & ${ }^{7} \mathrm{Li}:$ & ${ }^{6} \mathrm{Li}+{ }^{7} \mathrm{Li}$ & ${ }^{6} \mathrm{Li}$ & ${ }^{7} \mathrm{Li}$ & ${ }^{6} \mathrm{Li}+{ }^{7} \mathrm{Li}$ & & & ${ }^{6} \mathrm{Li}$ & ${ }^{7} \mathrm{Li}$ & ${ }^{6} \mathrm{Li}+{ }^{7} \mathrm{Li}$ \\
\hline & & \multicolumn{6}{|c|}{ (Tritium nıclei/incident neutron) } & & & \multicolumn{3}{|c|}{ (Tritium nuclei/incident neutron) } \\
\hline \multirow{2}{*}{$\begin{array}{l}\text { Primary lithium } \\
\text { region }\end{array}$} & 25 . & 0.623 & $0.4 C 9$ & 1.032 & 0.603 & 0.437 & 1.040 & \multirow[t]{2}{*}{$\begin{array}{l}\text { Primary lithium } \\
\text { region }\end{array}$} & 2.5 & 0.099 & 0.069 & 0.168 \\
\hline & & & & & & & $"$ & & 20.0 & 0.426 & 0.342 & 0.768 \\
\hline $\begin{array}{l}\text { Lithium behind } \\
\text { graphite refle:tor }\end{array}$ & 2.5 & $8.4 \times 10^{-2}$ & $6.4 \times 10^{-3}$ & 0.090 & 0.105 & 0.007 & 0.112 & & 2.5 & 0.082 & 0.025 & 0.107 \\
\hline \multirow[t]{4}{*}{$\begin{array}{l}\text { Lithium coolant } \\
\text { in gamma shield }\end{array}$} & 0.5 & $1.1 \times 10^{-2}$ & $7.5 \times 10^{-4}$ & 0.012 & $1.4 \times 10^{-2}$ & $7.9 \times 10^{-4}$ & $0.015^{\circ}$ & $\begin{array}{l}\text { Lithium behind } \\
\text { graphite reflector }\end{array}$ & 4.0 & 0.104 & 0.011 & 0.115 \\
\hline & 0.5 & $8.3 \times 10^{-3}$ & $4.7 \times 10^{-4}$ & 0.009 & $1.0 \times 10^{-2}$ & $5.0 \times 10^{-4}$ & 0.010 & ? & .. & & & \\
\hline & 0.5 & $7.0 \times 10^{-3}$ & $3.0 \times 10^{-4}$ & 0.007 & $8.4 \times 10^{-3}$ & $3.2 \times 10^{-4}$ & 0.009 & Lithium coolant & 1.18 & $2.6 \times 10^{-2}$ & $2.3 \times 10^{-3}$ & 0.029 \\
\hline & • & & & & & & & & 0.5 & $7.9 \times 10^{-3}$ & $7.0 \times 10^{-4}$ & 0.009 \\
\hline \multirow[t]{2}{*}{. } & & . & & & - & & $\therefore$ & - & 0.5 & $5.4 \times 10^{-3}$ & $4.5 \times 10^{-4}$ & 0.006 \\
\hline & $\cdot$ & & & & & & . & & 0.5 & $.3 .1 \times 10^{-3}$ & $2.9 \times 10^{-4}$ & 0.003 \\
\hline Total & & 0.733 & $0.4: 7$ & 1.150 & 0.740 & 0.445 & 1.186 & - & & 0.754 & 0.448 & 1.205 \\
\hline
\end{tabular}




\section{REFERENCES}

1. M. ROBERTS, Project Manager, "Oak Ridge Tokamak Experimental Power Reactor Study Scoping Report," ORNL/TM-5038, Oak Ridge National Laboratory (1975).

2. R. T. SANTORO, E. S. BETTIS, D. G. MCALEES, H. L. WATTS, and M. L. WILLIAMS, "Neutronic Scoping Studies for the Tokamak Experimental Power Reactor," ORNL/TM-5035, Oak RIdge National Laboratory (1976).

3. P. N. HAUBENREICH, Ed., "Tokamak Experimental Power Reactor: Basic Considerations and Initiation of Studies at 0ak Ridge," ORNL/TM-4853, Oak Ridge National Laboratory (1975).

4. M. ROBERTS and E. S. BETTIS, "Oak Ridge Tokamak Experimental Power Reactor Study - Reference Design," ORNL-TM-5042, Oak Ridge National Laboratory (1975).

5. R. T. SANTORO, "Neutronics Calculations for the Tokamak Experimental Power Reactor Reference Design," ORNL-TM-5033, Oak Ridge National Laboratory (1975).

6. G. L. KULCINSKI et al., "A Method to Reduce the Effects of Plasma Contamination and First Wall Erosion in Fusion Reactors," UWFDM-108, University of Wisconsin (1974).

7. C. A, FLANAGAN, "Nuclear Systems Status Report," presented at the Technology Workshop on Blanket/Power Systems for Fusion Reactors at Brookhaven National Laboratory, March 29 - Apri1 2, 1976. (unpublished).

8. M. ROBERTS et az., "Oak Ridge Tokamak Experimental Power Reactor Study - 1976," ORNL/TM-5572 through 5577, Oak Ridge National Laboratory (1976). 
9. M. L. WILlLIAMS, R. T. SANTORO; and T. A. GABRIEL, Nucl. Tech. $\underline{29}$, $384(1976)$.

10. M. A. ABDOU and R. W. CONN, Nucl. Sci. Eng. $\underline{55}, 256$ (1974).

11. D. STEINER, Nucl. Fusion 14, 33 (1974).

12. 'W. G. PRICE, Jr., "Blanket Neutronic Studies for a Fusion Power Reactor," Proc. Fifth Symp. on Engineering Problems in Fusion Research, Princeton University, November 5-9, 1973, IEEE Publication Nu. 73CH0843-3-NPS, P. 75.

13. W. W. ENGLE, Jr., "A User's Manual for ANISN, a One-Dimensional Discrete Ordinates Code with Anisotropic Scattering," Report K-1693, Computing Technology Center, Union Carbide Corporation (1967).

1.4. D. M. PLASTER, R. T. SANTORO, and W: E. FORD, III, "Coupled 100-Group Neutron and 21-Group Gamma-Ray Cross Sections for EPR Calculations," ORNL-TM-4872, Oak Ridge National Laboratory (1975).

15. W. E. FORD, III, R. T. SANTORO, R. W. ROUSSIN, and D. M. PLASTER, "Modification Number One to the Coupled 100n-21r Cross-Section Library for EPR Calculations," ORNL-TM-5249, Oak Ridge National Laboratory (1976).

16. G. D. JOANOU and J. S. DUDEK, "GAM II - a $B_{3}$ Code for the Calculation of Fast Neutron Spectra and Associated Multigroup Constants," GA-4265, General Atomic (1963).

17. M. A. ABDOU, C. W. MAYNARD, R. Q. WRIGHT, "MACK - A Computer Program to Calculate Neutron Energy Release Parameters (Fluence-to-Kerma Factors) and Multigroups Neutron Reaction Cross Sections from Nuclear Data in ENDF Format," ORNL-TM-3994, Oak Ridge National Laboratory (1973). 
18. M. A. ABDOU and R. W. ROUSSIN, "MACKLIB-100-Group Neutron Fluence-toKerma Factors and Reaction Cross Section Generated by the MACK Computer Program from Data in ENDF Format," ORNL-TM-3995, Oak Ridge National Laboratory (1974).

19. N. M. GREENE, et al., "AMPX: A Modular Code System for Generating Coupled Multigroup Neutron-Gamma Libraries from ENDF/B" ORNL-TM-3706, Oak Ridge National Laboratory (1976).

20. T. A. GABRIEL, J. D. AMBURGEY, N. M. GREENE, "Radiation-Damage Calculations: Primary Recoil Spectra, Displacement Rates, and GasProduction Rates," ORNL-TM-5160, Oak Ridge National Laboratory (1976).

21. F. B. SADLER and D. L. SELBY, "GOFRR: A Computer Code to Generate Graphical Output for Fluxes and Reaction Rates", ORNL-TM-5063, to be publishhed. 
1. L. S. Abbott

2. F. S. Alsmiller

3. R. G. Alsmiller, Jr.

4-5. J. M. Barnes

6. J. Barish

7. E. S. Bettis

8. J. F. Clarke

9. A. P. Fraas

10. T. A. Gabriel

11. F. Hammerling

12. G. Krist

13. R. A. Lillic

14. F. C. Maienschein

15. 0. B. Morgan, Jr.

16. F. R. Mynatt

17. E. M. Oblow

18. M. Roberts

19. M. W. Rosenthal

20. R. W. Rouss in

21. RSIC

22-41. R. T. Santoro
42. J. L. Scott

43. D. Steiner

44. M. L. Tobias

45. N. A. Uckan

46. J. S. Watson

47. C. R. Weisbin

48. G. E. Whitesides

49. A. Zucker

50. P. F. Fox (consultant)

51. W. W. Havens, Jr. (consultant)

52. A. F. Henry (consultant)

53. R. E. llhrig (consultant)

54-55. Central Research Library

56. ORNL Y-12 Technical Library Document Reference Section

57. Laboratory Records Department

58. Laboratory Records ORNL RC

59. ORNL Patent Office

\section{External Distribution}

60-61. V. Baker, Ebasco Services, Inc., Two Rector St., New York, NY 10006.

62. H. Goldstein, Columbia University, 287A Mudd Building, New York, NY 10027.

63-89. Technical Information Center (TIC).

90. U. S. ERDA Oak Ridge Operations, Research and Technical Support Division, P. O. Box E, Oak Ridge, TN 37830: Director.

91-136. Given NPD-CTR External Distribution. 